\title{
ESTUDDDS DOCTRINALES
}

\section{APROXIMACIÓN LABORAL A LOS CONCEPTOS DE ESCLAVITUD, TRABAJO FORZOSO Y EXPLOTACIÓN LABORAL EN LOS TRATADOS INTERNACIONALES*}

\section{LABOUR APPROACH TO THE CONCEPTS OF SLAVERY, FORCED LABOUR AND LABOUR EXPLOITATION IN INTERNATIONAL TREATIES}

\author{
Pilar Rivas Vallejo \\ Catedrática de Derecho del Trabajo y de la Seguridad Social \\ Universidad de Barcelona \\ pilar.rivas.vallejo@ub.edu ORCID0000-0002-1766-7659
}

Recepción de trabajo: 10-03-2021 - Aceptación: 11-04-2021

—1. FRONTERAS ENTRE EL TRABAJO FORZOSO, LA ESCLAVITUD, LA SERVIDUMBRE Y LA EXPLOTACIÓN LABORAL. 1.1. Introducción. 1.2. Fronteras difusas como punto de partida. 1.3. Delimitación de fronteras entre los diversos términos y conceptos. $\square$ 2. CONCEPTO DE TRABAJO FORZOSO. 2.1. Introducción. 2.2. Elementos caracterizadores. 2.3. Exclusiones. 2.4. Finali-

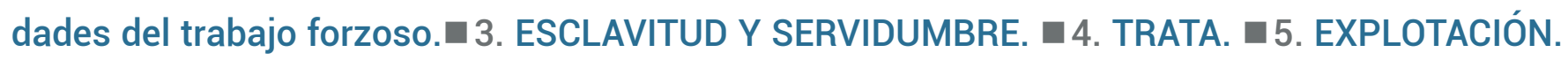
5.1. Explotación del trabajo y explotación de la persona. 5.2. Imposición de condiciones laborales abusivas y trabajo decente. $\square$ 6. SITUACIONES LABORALES FRONTERIZAS. 6.1. Condiciones laborales abusivas frente a condiciones laborales ilegales. 6.2. Integridad moral y trato degradante. 6.3. Limitación del derecho de libertad. $\square$ 7. Conclusiones.

\footnotetext{
* El presente trabajo constituye una versión de otro contenido en la obra Formas contemporáneas de esclavitud y derechos humanos en clave de globalización, género y trata de personas. Tirant lo Blanch, Valencia, 2020 ((Pedro Mercado Pacheco, María Inmaculada Ramos Tapia; Esteban Juan Pérez Alonso, Sofía Olarte Encabo, dirs.), publicada con el título "Las fronteras entre los conceptos de esclavitud, trabajo forzoso y explotación: perspectiva laboral y de género" en el contexto del proyecto de investigación Formas contemporáneas de esclavitud. Subproyecto: Zonas grises de la esclavitud femenina: servicio doméstico, prostitución, matrimonios forzados y trabajo de niñas. Plan Nacional. Ministerio de Ciencia e Innovación. Ref. DER2014-56417-C3-2-P, bajo el título "Las fronteras entre los conceptos de esclavitud, trabajo forzoso y explotación: perspectiva laboral y de género".
} 


\section{RESUMEN}

En este trabajo se abordan los conceptos de esclavitud, servidumbre y trabajo forzoso y explotación laboral para la búsqueda de sus líneas divisorias, así como los límites legales y consecuencias jurídicas.

PALABRAS CLAVE: esclavitud, trabajo forzoso, explotación laboral.

\section{ABSTRACT}

The aim of this article is to analyze the concepts of slavery, servitude and forced labour and labour exploitation are addressed in order to search for their dividing lines, as well as the legal limits and legal consequences.

KEYWORDS: slavery, servitude, forced labour, labour exploitation. 


\section{FRONTERAS ENTRE EL TRABAJO FORZOSO, LA ESCLAVITUD, LA SERVIDUMBRE Y LA EXPLOTACIÓN LABORAL}

\subsection{Introducción}

A los fines de las próximas páginas, dedicadas a trazar los lindes conceptuales entre las diversas figuras que comprometen la voluntariedad del trabajo y el trato humano de las y los trabajadores, en un intento de aproximación a la distinción entre las diversas formas de explotación forzada de la persona con fines lucrativos, se ha optado por contextualizar el análisis en el ámbito del trabajo.

El eje conceptual del trabajo será la herramienta que permita ir separando conceptualmente diversos casos en los que la persona es explotada con fines lucrativos más allá de la legalidad aplicable y, lo que es más importante, más allá de los límites de los derechos humanos, basculando entre la voluntariedad en la prestación de un trabajo y el sometimiento a esclavitud forzada y, especialmente, sobre el elemento de la reducción de la persona a un esquema de equiparación a los atributos de la propiedad bajo el yugo de la coacción, la amenaza o la intimidación, en cualquier grado de una posible escala de intensidades de heterocontrol.

\subsection{Fronteras difusas como punto de partida}

La Organización Internacional del Trabajo es consciente de la confusión conceptual en torno a las prácticas o formas contemporáneas de esclavitud, reconociendo la existencia de un debate abierto sobre el concepto jurídico de trabajo forzoso y otras prácticas abusivas conexas (entre ellas, la trata de personas, la esclavitud y las prácticas análogas a la esclavitud, la servidumbre por deudas o el trabajo en régimen de servidumbre, y la explotación laboral)', que la propia Organización Internacional del Trabajo (OIT) intentó revisitar en 2007 a través de su Comisión de Expertos en Aplicación de Convenios y Recomendaciones para considerar formas nuevas de trabajo forzoso que conviven con las tradicionales esclavitud, trata de personas, servidumbre y trabajo forzoso ${ }^{2}$. En su Estudio general de 15 de febrero de $2007^{3}$ (en adelante “Estudio 2007") cita la esclavitud, las prácticas aná-

1 OIT: Informe Global de la 0IT, El costo de la coacción, 5 de diciembre de 2009, en http://www.ilo.org/wcmsp5/groups/public/---ed_norm/---declaration/ documents/publication/wems_106269.pdf. Articulo 8 del Pacto Internacional de Derechos Civiles y Políticos (adoptado y abierto a la firma, ratificación y adhesión por la Asamblea General en su resolución 2200 A (XXI), de 16 de diciembre de 1966, http://www.ohchr.org/SP/Professionallnterest/Pages/CCPR.aspx).

3 Informe III (Parte 1B). Estudio general relativo al Convenio sobre el trabajo forzoso, 1930 (núm. 29), y al Convenio sobre la abolición del trabajo forzoso, 1957 (núm. 105). Conferencia Internacional del Trabajo 96. ${ }^{a}$ reunión, 2007. Publicado en http://www.ilo.org/wcmsp5/groups/public/---ed_norm/---relconf/documents/meetingdocument/wcms_089201.pdf. 
logas a la esclavitud y otras formas ilícitas de coacción para trabajar; la trata de personas con fines de explotación; el trabajo forzoso u obligatorio impuesto por el Estado con fines de producción o de servicio; la privatización de las cárceles y el trabajo penitenciario; la pena de prestación de trabajo de utilidad pública; el trabajo obligatorio como condición para percibir prestaciones por desempleo y la obligación de realizar horas extraordinarias so pena de sanción.

Este fenómeno es, además, creciente con la mundialización de la economía, que ha arropado fenómenos de delincuencia transnacional organizada en relación con la trata de personas, y ha dado cobertura a situaciones a menudo límite con el concepto clásico de la esclavitud o el más atenuado del trabajo forzoso, a veces escondidas bajo una invisibilidad ${ }^{4}$ especialmente cruel con las mujeres ${ }^{5}$. Muchos son los que han pretendido profundizar en la conceptuación de todos estos fenómenos, intentando clarificar sus fronteras, tanto entre la doctrina académica ${ }^{6}$ como en la jurisprudencia. Por eso las siguientes páginas serán un intento más de llegar a alguna conclusión al respecto, tanto en el marco legislativo internacional como en el caso particular del derecho español desde la perspectiva laboralista?.

Salas Porras, María: "Trabajador esclavo y contrato de esclavo: configuración juridica", Revista Critica de Historia de las Relaciones Laborales y de la Politica Social. 2014, reimpresión en número 38, 2016, en http://www.eumed.net/rev/historia/08/contrato-esclavo.html, p. 29, y Urrutikoetxea Barrutia, Mikel: "No se ve, no se toca y sin embargo, existe: La esclavitud hoy. Hacia una reconceptualización del trabajo esclavo", Lan harremanak: Revista de relaciones laborales, núm. 35, 2017, pp. 391 y 392.

5 Lousada Arochena, J. Fernando: "Normativa internacional contra la explotación humana y laboral en el trabajo doméstico: La ONU y la OIT", Lan harremanak: Revista de relaciones laborales, núm. 39, 2018, en https://dialnet.unirioja.es/descarga/articulo/6550623.pdf, p. 156. El autor incide en el binomio invisibilidad y aislamiento que caracteriza al trabajo doméstico, especialmente el que tiene lugar en régimen de internamiento, cuyo tratamiento social a menudo resta importancia a su verdadera gravedad.

6 Valga como referente la obra colectiva dirigida por Esteban Juan Pérez Alonso, Pedro Mercado Pacheco, Sofía Olarte Encabo, Ángeles Lara Aguado, María Inmaculada Ramos Tapia, Esther Pomares Cintas, y Patricia Esquinas Valverde: El derecho ante las formas contemporáneas de esclavitud, Tirant lo Blanch, 2017. En particular, los capitulos de Jordi Bonet Pérez: "La interpretación de los conceptos de esclavitud y de otras prácticas análogas a la luz de ordenamiento juridico internacional: Aproximación teórica y jurisdiccional", pp. 183-210, y de Martín Morales, Ricardo: "Las nuevas formas de esclavitud en los textos constitucionales y declaraciones de derechos", pp. 281-305. Asimismo, AA.VV. (Pedro Mercado Pacheco, María Inmaculada Ramos Tapia; Esteban Juan Pérez Alonso, Sofia Olarte Encabo, dirs.): Formas contemporáneas de esclavitud y derechos humanos en clave de globalización, género y trata de personas, Tirant Io Blanch, 2020.

7 En el ámbito laboral, vid. especialmente Rojo Torrecilla, Eduardo: "Nueva esclavitud y trabajo forzoso: un intento de delimitación conceptual desde la perspectiva laboral", en AA.VV.: El derecho ante las formas contemporáneas de esclavitud, op.cit. pp. 721-755. Vid. asimismo la tesis doctoral realizada por García Schwarz, Rodrigo: Rompiendo las cadenas de una ciudadanía cautiva. De los derechos sociales a los derechos humanos fundamentales. La lucha contra el trabajo esclavo contemporáneo. Tesis doctoral dirigida por Laura Mora Cabello de Alba (dir. tes.). Universidad de Castilla-La Mancha (2010). Desde una perspectiva penalista-laboralista, vid. los trabajos de Esther Pomares Cintas, y, en particular: "Directrices para el análisis y persecución penal de la explotación económica en condiciones de esclavitud o similares". En AA.VV:: El derecho ante las formas contemporáneas de esclavitud, op.cit, pp. 775-794. Asi como los de Carolina Villacampa, especialmente "La moderna esclavitud y su relevancia jurídico-penal", Revista de derecho penal y criminología, 3. época, n. ${ }^{0} 10$ (julio de 2013), pp. 293-342, http://e-spacio.uned.es/fez/eserv/bibliuned:revistaDerechoPenalyCriminologia-2013-10-4035/Documento.pdf. Igualmente, López Rodriguez, Josune, y Arrieta Idiakez, Francisco Javier: "La trata de seres humanos con fines de explotación laboral en la legislación española", ICADE. Revista cuatrimestral de las Facultades de Derecho y Ciencias Económicas y Empresariales, núm. 107, 2019, D0l: https://doi.org/10.14422/icade.i107.y2019.002. 
El punto de partida es, sin duda, la Declaración Universal de Derechos Humanos, proclamada por la Asamblea General de las Naciones Unidas en París el 10 de diciembre de 1948 en su Resolución 217 A (III) ${ }^{8}$ como "Declaración Universal de los Derechos del Hombre", cuyo artículo 4 declara que "nadie estará sometido a esclavitud ni a servidumbre, la esclavitud y la trata de esclavos están prohibidas en todas sus formas". Pues, aunque la Declaración relativa a la abolición universal de la trata de esclavos, adoptada por el Congreso de Viena en $1815^{\circ}$, es el primer instrumento internacional en condenar la esclavitud, no constituye el marco legal vigente de referencia (no sólo por la ausencia de carácter vinculante).

Pero, antes de esta proclamación, la primera de las agencias creadas por Naciones Unidas, la OIT ya había aprobado un texto legal en el que se regulaba el trabajo forzoso ${ }^{10}$, dando así lugar a la importante distinción que pretende analizarse en las siguientes páginas, esto es, la delimitación entre trabajo forzoso, esclavitud laboral, servidumbre y explotación laboral a la luz de los textos internacionales. Considerando, asimismo, que uno de los principios de la Declaración relativa a los fines y objetivos de la OIT (Declaración de Filadelfia), integrada como anexo a la Constitución de la OIT en 1944, por la que se establecen los principios, fines y objetivos de la organización, es el que reza: "el trabajo no es una mercancía"1. Ni lo es el trabajo ni, por supuesto, lo puede ser quien lo presta o desarrolla.

\subsection{Delimitación de fronteras entre los diversos términos y conceptos}

Trata, explotación, trabajo forzoso, esclavitud y servidumbre son conceptos que a menudo se manejan indistintamente, pero que no son sinónimos. Y, si bien distintos textos legislativos han establecido su propia definición de algunos o la mayoría de estas figuras, lo cierto es que han conformado un consenso mundial, al haberse inspirado los textos regionales en dos grandes referentes legislativos en esta materia: el Convenio número 29 de la OIT de 1930 (y su complementario 105 de 1956)12 y el Protocolo para prevenir, reprimir y sancionar la trata de personas, especialmente mujeres y niños de 2000, también llamado Protocolo de Palermo, este último complementario de la Convención sobre la esclavitud de 1926 y de la Convención suplementaria de 1956.

Consultable en http://www.un.org/es/comun/docs/?symbol=A/RES/217(III).

9 Declaración de 8 de febrero de 1815, Consolidated Treaty Series, vol. 63, núm. 473.

10 El primero de ellos fue la Convención sobre la esclavitud de 1926, Convención de 1926 sobre esclavitud, servidumbre, trabajo forzoso e instituciones y prácticas análogas, League of Nations Treaty Series, vol. 60. En ella se establece que «el trabajo forzoso u obligatorio no podrá exigirse más que para fines de utilidad pública» y que los Estados parte «tomarán las medidas pertinentes para evitar que el trabajo forzoso u obligatorio lleve consigo condiciones análogas a la esclavitud» (artículo 5). Al mismo siguió el Convenio sobre trabajo forzoso de la 0IT pocos años después (1930).

11 Como bien sintetiza uno de los directores generales que ha tenido la 0IT, Juan Somavía (Director General de la 0IT entre 1999 y 2012), "no podemos reducir el trabajo a su dimensión puramente mercantil, es la razón por la cual la OIT dice que el trabajo no es una mercancía sino un bien social". Desde el punto de vista económico, añade, existe efectivamente un mercado laboral, pero para el ser humano, el trabajo es fuente de dignidad personal, es fuente de estabilidad, es factor de cohesión social.

12 Vid. desde una perspectiva laboralista Cavas Martínez, Faustino: "Trabajo libre, trabajo digno: revisando viejas ideas a propósito de un reciente informe de la OIT sobre el trabajo forzoso en el mundo", en Aranzadi social, núm. 5, 2001, pp. 83-96. 
APROXIMACIÓN LABORAL A LOS CONCEPTOS DE ESCLAVITUD, TRABAJO FORZOSO Y EXPLOTACIÓN LABORAL

Tanto las Naciones Unidas como la OIT han simultaneado su construcción de los conceptos de trabajo forzoso y de esclavitud y trata en los años 1926 y 1956 (los convenios originarios en 1926 y sus complementarios en 1956). Si bien el concepto de esclavitud y de servidumbre no se definen por la OIT, que se centra en la figura del "trabajo forzoso", mientras que el de esclavitud y trata resultan regulados por las convenciones de Naciones Unidas, así como de otras de ámbito regional europeo (Convenio Europeo para la Protección de los Derechos Humanos y de las Libertades Fundamentales de 1950), americano (Convención Americana de Derechos Humanos) o africano (Carta Africana sobre los Derechos Humanos y de los Pueblos).

Estos textos, que reposan en las ideas maestras de interés general, de solidaridad y de normalidad, han inspirado los convenios regionales sobre derechos humanos en todo el mundo, sirviendo asimismo de inspiración para su interpretación por parte de los distintos tribunales internacionales o regionales de Justicia, como ordena el Convenio de Viena de 1969 sobre el derecho de los tratados en su artículo 31.3 c). Así, el Tribunal Europeo de Derechos Humanos (TEDH), la Corte Interamericana de Derechos Humanos (CIDH), la Corte de Justicia de la Comunidad Económica de África Occidental o el Tribunal Penal Internacional para la ex Yugoslavia ${ }^{13}$, han confluido en una interpretación común de estos términos, siendo sus sentencias una declaración de intenciones de este propósito. Sin embargo, sus interpretaciones no siempre son idénticas, aun cuando sí comparten un sustrato o inspiración común. Según proclama el TEDH, "existe una analogía sorprendente, que no es fortuita, entre el párrafo 3 del artículo 4 del Convenio y el párrafo 2 del artículo 2 del Convenio núm. 29 de la OIT" (sentencia de 21 de enero de 2016, caso L.E. contra Grecia). Y el mismo tribunal confiesa haber tomado la definición del artículo 4.3 del convenio núm. 29 de la OIT como punto de partida para su interpretación del artículo 4 del Convenio europeo.

Si para unos tribunales la atención recae sobre el trabajo forzoso y la trata (TEDH), para otros la esclavitud y la servidumbre parecen ser la figura central, en tanto que formas especialmente agravadas, que pueden contener el resto de las formas de coacción de la voluntad de las personas para realizar un trabajo. Todos ellos convienen, asimismo, en que el fenómeno de la esclavitud, lejos de ser un vestigio histórico, es una figura incluso en auge, que se ha sofisticado en sus formas de ejecución, especialmente desde un punto de vista organizativo transnacional, reinventando las antiguas redes de trata de esclavos. Como en la época del colonialismo, el nuevo colonialismo económico del actual capitalismo rentabiliza estos modos de explotación humana, y, aunque no eleva ya a la categoría de institución legal sus formas, pues, al contrario, las proscribe y manda perseguir, hipócritamente las tolera como sistemas de enriquecimiento de redes económicas, lejos de una estructura simple de elementos mafiosos marginales. Por otra parte, los sistemas legales que regulan el trabajo no cuentan o no tienen especial interés por la persecución de las formas de explotación de las víctimas

13 Vid. al respecto Olarte Encabo, Sofía: "La doctrina del Tribunal Europeo de derechos humanos sobre esclavitud, servidumbre y trabajo forzado: Análisis crítico desde la perspectiva laboral", Temas laborales: Revista andaluza de trabajo y bienestar social, núm. 145, 2018 (La jurisprudencia del Tribunal Europeo de Derechos Humanos en materia laboral. In memoriam José Vida Soria), pp. 55-86. 
APROXIMACIÓN LABORAL A LOS CONCEPTOS DE ESCLAVITUD, TRABAJO FORZOSO Y EXPLOTACIÓN LABORAL

principales del trabajo forzoso: los trabajadores migrantes, especialmente las mujeres. El sesgo de género explica su olvido por parte de nuestros legisladores hasta décadas muy recientes ${ }^{14}$.

Todas las figuras, sean la clásica o las más contemporáneas, tienen un elemento común que se erige en finalidad del trato infligido a la víctima: obtener un beneficio económico de esta, y en todos los casos se entiende que la aplicación del concepto debe realizarse "a la luz de las concepciones que imperan en nuestros días en los Estados democráticos". Cómo se obtenga y bajo qué circunstancias es lo que funda, en la jurisprudencia de los distintos tribunales, la distinción entre unas figuras y otras. Y, así, mientras el beneficio económico del trabajo ajeno obtenido de forma coactiva es el elemento clave y finalidad perseguida en unos casos, en otros constituye sólo una de las finalidades perseguidas o bien sólo uno de los elementos definidores de la situación. Puede decirse que la obtención de ese beneficio a partir de la explotación de la persona deriva de distintas formas de coacción, y esta diversidad es la que provoca que sea de aplicación una u otra figura, tanto a adultos como a menores (sin perjuicio del plus de protección que la legislación sobre protección a la infancia o trabajo de menores les otorga):

- Esclavitud: se vertebra sobre la idea de propiedad en la Convención sobre la esclavitud de 1926 y su Convención suplementaria de 1957, pero este elemento vertebrador pervive hoy día en el Estatuto de Roma. Prueba de esta actualidad es la jurisprudencia de la Corte Interamericana de Derechos Humanos (CIDH), cuya sentencia de 20 octubre de 2016, caso de los trabajadores de la Hacienda Brasil Verde contra Brasil, considera que los dos elementos fundamentales para definir una situación como esclavitud son el estado o condición de un individuo y el ejercicio de alguno de los atributos del derecho de propiedad, es decir, que el esclavizador ejerza poder o control sobre la persona esclavizada al punto de anular la personalidad de la víctima". El concepto de propiedad cobra una relevancia para la CIDH de la que carece bajo la jurisprudencia del TEDH. A tenor del tribunal interamericano, "para determinar una situación como esclavitud en los días actuales, se deberá evaluar la manifestación de los llamados "atributos del derecho de propiedad”, que son: “a) restricción o control de la autonomía individual; b) pérdida o restricción de la libertad de movimiento de una persona; c) la obtención de un provecho por parte del perpetrador; d) la ausencia de consentimiento o de libre albedrío de la víctima, o su imposibilidad o irrelevancia debido a la amenaza de uso de la violencia u otras formas de coerción, el miedo de violencia, el engaño o las falsas promesas; e) el uso de violencia física o psicológica; f) la posición de vulnerabilidad de la víctima; g) la detención o cautiverio, i) la explotación". Para la corte interamericana "lo importante actualmente no es la existencia de un título de propiedad

Aunque no por la doctrina científica. Cfr. Lousada Arochena, J. Fernando: "Normativa internacional contra la explotación humana y laboral en el trabajo doméstico: La ONU y la 0IT", Lan harremanak: Revista de relaciones laborales, núm. 39, 2018, pp. 152-187, https://dialnet.unirioja.es/descarga/articulo/6550623. pdf. Asimismo, Lerussi, Romina: "Servidumbres domésticas en contextos latinoamericanos: Aproximaciones socio-jurídicas". En AA.VV.: El derecho ante las formas contemporáneas de esclavitud, op.cit., pp. 757-774. Y Min̂arro Yanini, Margarita: «Formas esclavas de trabajo y servicio del hogar familiar: delimitación conceptual, problemática especifica y propuestas (1), Relaciones Laborales, n. ${ }^{0} 10$, Sección Doctrina, octubre 2014, año 30, pp. 71 y ss. 
APROXIMACIÓN LABORAL A LOS CONCEPTOS DE ESCLAVITUD, TRABAJO FORZOSO Y EXPLOTACIÓN LABORAL

sobre el esclavo, sino el ejercicio de poderes vinculados con la propiedad que se traducen en la destrucción o anulación de la personalidad jurídica del ser humano".

- Servidumbre: si los convenios internacionales y regionales separan esta figura de la esclavitud, a la que denominan forma análoga, por tanto, equiparable pero no idéntica, la Corte Interamericana de Derechos Humanos da un paso más hacia la plena equiparación, concluyendo que se trata de situaciones idénticas, aunque la servidumbre puede considerarse una forma más contemporánea de referirse al mismo fenómeno, el de la clásica esclavitud. La jurisprudencia del TEDH la identifica con la obligación de prestar servicios bajo el imperio de la coacción (asunto Siliadin, 2005 ${ }^{15}$ ), junto con la percepción de las víctimas respecto del carácter temporal o permanente e irreversible de su situación (caso Chowdury y otros contra Grecia, 2017). El TEDH matiza en cualquier caso que el término explotación debe reservarse exclusivamente para la trata de personas.

- Trabajo forzoso: el TEDH distingue trabajo forzado de trabajo obligatorio, por asociar al primero a una coacción física o moral, mientras en el segundo se trata de una obligación jurídica, aunque no de una obligación jurídica cualquiera, sino del "exigido bajo la amenaza de una pena" y además contra la voluntad del interesado, para el que "no se ha ofrecido por propia voluntad", que es precisamente la definición del trabajo forzoso del convenio número 29, en el que se equipara trabajo forzoso y trabajo obligatorio. El trabajo forzoso se identifica con el prestado de manera obligatoria por coacción privada (por exclusión de ciertas formas de carácter público como las prestaciones cívicas, que la OIT excluye con carácter general bajo condiciones de proporcionalidad en sociedades democráticas) dirigida a obtener la doblegación de la voluntad de la persona de manera violenta o de manera sutil, pero en todo caso garantizada por la amenaza de una pena o represalia, del tipo que sea (desde la amenaza de un daño físico a la víctima o a un tercero, la amenaza de denuncia a las autoridades, ...hasta la privación de cualquier derecho, ventaja o privilegio personal o laboral), suficiente para amedrentar a la víctima y, según sus propias circunstancias, sentirse coaccionada a prestarse a la explotación para evitar otro mal al que teme más que a una prestación de servicios forzada, bajo el denominador común de explotación de la vulnerabilidad del trabajador. El trabajo forzoso no conlleva en sí, según resulta definido, una privación de otro tipo, a tenor de la definición del convenio de la OIT según se interpreta en los diferentes estudios generales realizados por la comisión destinada a ello, como la salarial o la de descanso, pero, si esta concurre, resulta incompatible con el concepto de trabajo forzoso, pudiendo invadir las fronteras de otra figura, la de la servidumbre, como se interpreta por la jurisprudencia del TEDH. En esta, la servidumbre representa un plus sobre el trabajo forzoso en cuanto no solo supone la falta de voluntad y realización de un trabajo bajo alguna forma coactiva, sino que además las condiciones de trabajo, e incluso de vida, comportan

15 Vid. un comentario sobre esta sentencia en Boronat Tormo, Mercedes y Grima Lizandra, Vicente: "La esclavitud y la servidumbre en el derecho español. A propósito de la STEDH de 26 de julio de 2005 ("Siliadin vs. Francia"): un caso de trabajo doméstico servil", en Carbonell Mateu, J. C.; González Cussac, J. L; Orts Berenguer, E. y Cuerda Arnau, Ma. L. (Coord.), Constitución, derechos fundamentales y sistema penal: (Semblanzas y estudios con motivo del setenta aniversario del profesor Tomás Salvador Vives Antón), vol. 1, 2009, pp. 257-286. 
APROXIMACIÓN LABORAL A LOS CONCEPTOS DE ESCLAVITUD, TRABAJO FORZOSO Y EXPLOTACIÓN LABORAL

otras vulneraciones, graves, de derechos fundamentales, como la del salario, de movimientos, de descanso, de libertad en definitiva, más allá del lugar de trabajo y proyectada sobre la forma de vida de la víctima y contraria a su dignidad, con una vocación de permanencia o de imposibilidad para ponerle fin que llega a socavar la resistencia psicológica de la víctima. En definitiva, una persona sometida a servidumbre lo es también a trabajo forzoso, pero no, necesariamente, al contrario. Y ello es así porque el trabajo forzoso puede concurrir en el contexto de un empleo estándar, mientras que la servidumbre se define en sí misma por su carácter patológico. No en vano el Protocolo de 2014 relativo al Convenio sobre el trabajo forzoso de la OIT de 2014 nos recuerda que la definición de trabajo forzoso u obligatorio prevista en el artículo 2 del Convenio abarca el trabajo forzoso u obligatorio en todas sus formas y manifestaciones. Pero es obvio que estas pueden graduarse en su gravedad desde un nivel muy bajo hasta formas muy graves.

- Trata: Ia OIT asocia estas formas de trabajo forzoso con condiciones de trabajo particularmente duras y abusivas, o "condiciones de trabajo incompatibles con la dignidad humana». Pero esta característica es común a la servidumbre. La diferencia estriba en la forma aplicada para Ilegar a este resultado, el del fin de la explotación que persigue la trata. Su esencia es que la trata persigue fines de explotación de la persona, y se caracteriza por la consideración de esta como una mercancía, siendo el objeto del tráfico el servicio o utilidad económica que puede obtenerse de ella y no su mera propiedad.

¿Y dónde entra la explotación laboral? La respuesta es que en todas y en ninguna. En todas forma parte de los rasgos de la figura, pero solo en un caso es el elemento determinante. Y este caso es el que puede tener tintes puramente laborales o bien incluso penales, como ocurre en el Código penal español, que tipifica la explotación laboral en el artículo 311, al regular la aplicación de condiciones ilegales como delito.

Como advierte la OIT en su informe global de 2009, se trata de un concepto que no cuenta con precedentes legislativos, ni internacionales ni nacionales. Su convención suplementaria 105 marca una diferencia entre explotación de la persona y explotación del trabajo de la persona en su apartado d), lo que permite atisbar una distinción entre esclavitud y trabajo forzoso (con el que identificar la "explotación laboral").

Y también el Protocolo de Palermo en su artículo 3 sugiere que la trata de personas con el fin de someterlas a trabajo forzoso constituye una modalidad de explotación relacionada con el trabajo, junto con la esclavitud o las prácticas análogas a la esclavitud, o la servidumbre. Sin embargo, no se refieren como concepto autónomo a la explotación, más allá de aludir a la finalidad perseguida por la trata. No así el derecho español, que regula una figura que, aunque no se denomina explícitamente como tal, sí puede considerarse una figura que tipifica la explotación laboral y que consiste en la imposición de condiciones de trabajo ilegales (artículo 311 del Código penal).

Su represión es perseguida penalmente, pero también por otras vías, si bien las formas más graves cuentan con un aparato conceptual y represor propio y universal como es el Estatuto de Roma 
APROXIMACIÓN LABORAL A LOS CONCEPTOS DE ESCLAVITUD, TRABAJO FORZOSO Y EXPLOTACIÓN LABORAL

y la Corte Penal Internacional que le da vida para la persecución de crímenes de lesa humanidad, entre los que se encuentra la esclavitud.

Para la OIT, el núcleo se centra en el carácter forzoso del trabajo, sobre el que pueden orbitar distintas formas de imponerlo y la condición que sobre la persona crean, más o menos limitada en su dignidad y en sus derechos, mientras que, para las Naciones Unidas, singularmente el Protocolo de Palermo, la trata de personas para someterlas a trabajo forzoso es únicamente una forma de explotación relacionada con el trabajo, junto con la esclavitud o las prácticas análogas a la esclavitud, o la servidumbre.

Asimismo, parece haberse posicionado como eje central en todas las figuras analizadas el factor de la vulnerabilidad. Como indica el Índice General de Esclavitud 2016, la vulnerabilidad para ser explotado o riesgo de explotación puede ser identificada por una serie de variables condicionantes, como son los índices de paz, democracia, corrupción, derechos humanos y acceso a servicios sociales. El entorno conformado por la combinación de estos factores es el que determina a su vez el índice de vulnerabilidad del país para generar riesgo de explotación, que se dispara si concurre una combinación de alta inestabilidad política, baja confianza en el sistema judicial y elevados índices de criminalidad, corrupción y discriminación.

Según la OIT, en su informe de diciembre de 2017 ya citado, el 71\% de los casos de esclavitud en el mundo lo son de mujeres y niñas. Sin embargo, la atención principal, incluso en el tratamiento de la cuestión desde la literatura científica, siempre se detiene sobre los casos, especialmente los judicializados, protagonizados por hombres de cualquier edad. El sesgo de género está presente tanto en el abordaje científico como en las acciones institucionales, que reservan para las mujeres las campañas relacionadas con la trata de personas, donde se concentra el grueso de las distintas formas de esclavitud moderna. Siendo ello así, lo cierto es que a menudo se soslayan otras parcelas de explotación humana extrema donde la presencia de mujeres y niñas es mayoritaria, y, por otra parte, no se advierte el sesgo de género presente en las decisiones judiciales que resuelven los casos judicializados ${ }^{16}$, que advierten un plus de antijuridicidad en circunstancias de explotación que envuelven a hombres sobre las típicamente femeninas (servidumbre). Y es que la segregación de las circunstancias esclavizantes según sexos lleva aparejada también una distinta respuesta institucional y judicial, sobre la que debería profundizarse más ampliamente.

16 Cfr. Gallo, Patricia: "Talleres textiles clandestinos en Argentina: ¿trabajo esclavo o explotación laboral?", en AA.VV. (Pedro Mercado Pacheco, María Inmaculada Ramos Tapia; Esteban Juan Pérez Alonso, Sofía Olarte Encabo, dirs.): Formas contemporáneas de esclavitud y derechos humanos en clave de globalización, género y trata de personas, Tirant lo Blanch, 2020, pp. 221-238. Asimismo, y en relación con el elemento central de la vulnerabilidad, Pacecca, María Inés: "Trabajo, explotación laboral, trata de personas. Categorías en cuestión en las trayectorias migratorias". Revista Interdisciplinar da Mobilidade Humana: REMHU, Vol. 19, núm. 37, 2011, en http://remhu.csem.org.br/index.php/remhu/article/view/281, que analiza la delimitación de los conceptos estudiados a la luz de la jurisprudencia argentina. 


\section{CONCEPTO DE TRABAJO FORZOSO}

La Sentencia del TEDH de 23 de noviembre de 1983, caso Van der Mussele contra Bélgica, mantiene que el convenio (CEDH) no determina qué se entiende por trabajo "forzado u obligatorio" y los diversos documentos del Consejo de Europa en donde se cita no dan indicaciones concretas sobre este punto, pues sus redactores - y ejemplo de ello es el artículo 8 del proyecto del Pacto internacional relativo a los derechos civiles y políticos - se han inspirado en gran medida en un tratado anterior sobre la Organización Internacional del Trabajo: el Convenio número 29 referente al trabajo forzado u obligatorio. Como se ha afirmado por la doctrina, se trata de un texto en vigor, pese a distintos textos legales posteriores han eludido usar su definición del trabajo forzoso, lo que también permite dudar acerca de su efectiva vigencia ${ }^{17}$. Ello, sin embargo y aun bajo tal prisma, no ha impedido que su filosofía se incorpore en otros textos legales y en su interpretación, avalada por los sucesivos estudios generales del Comité de Expertos en la Aplicación de Convenios y Recomendaciones, así como por el Protocolo de 2014, relativo al Convenio sobre el trabajo forzoso.

Por otra parte, en la sentencia anteriormente citada se distingue el trabajo forzado del obligatorio ${ }^{18}$, porque el primero de ellos evoca una coacción física o moral, mientras el segundo se asocia a una obligación jurídica, aunque no a una obligación jurídica cualquiera, sino al "exigido bajo la amenaza de una pena" y además contra la voluntad del interesado, para el que "no se ha ofrecido por propia voluntad", que es precisamente la definición del trabajo forzoso del convenio número 29, en el que se equiparan trabajo forzoso y trabajo obligatorio.

Pero también se afirma por el citado tribunal que "existe una analogía sorprendente, que no es fortuita, entre el párrafo 3 del artículo 4 del Convenio y el párrafo 2 del artículo 2 del Convenio núm. 29 de la OIT" (sentencia de 21 de enero de 2016, caso L.E. contra Grecia). Y que el Tribunal tomó la definición del artículo 4.3 del convenio núm. 29 de la OIT como punto de partida para su interpretación del artículo 4 del Convenio europeo, debiéndose examinar "a la luz de las concepciones que imperan en nuestros días en los Estados democráticos" (sentencia de 23 de noviembre de 1983, caso Van der Mussele contra Bélgica).

Por otra parte, la sentencia de 21 de enero de 2016, caso L.E. contra Grecia, sostiene que "la estructura específica del artículo 4, cuyo apartado 3 no tiende a "limitar" el ejercicio del derecho garantizado por el apartado 2 sino a "delimitar" el contenido propio de este derecho, pues forma un todo con el apartado 2 e indica lo que no está considerado como trabajo "forzoso u obligatorio". Es decir, el

17 Valverde Cano, Ana Belén: "It's all about control: el concepto de trabajos forzosos", Revista de Derecho Penal y Criminología, núm. 22, 2019, pp. 249-250, en http://revistas.uned.es/index.php/RDPC/article/view/27490.

18 Sobre esta distinción a la luz del derecho internacional, vid. Valverde Cano, Ana Belén: "It's all about control: el concepto de trabajos forzosos", Revista de Derecho Penal y Criminología, núm. 22, 2019, pp. 239-299, en http://revistas.uned.es/index.php/RDPC/article/view/27490. La autora establece como elemento de distinción el "continuum" en el control sobre la persona sometida al trabajo forzoso. 
apartado 3 contribuye a interpretar el apartado 2. Sus cuatro subpárrafos, más allá de su diversidad, reposan en las ideas maestras de interés general, de solidaridad y de normalidad".

Aunque el Comité de Derechos Humanos, por su parte, en su interpretación del art. 8 del Pacto Internacional de Derechos Civiles y Políticos, define el concepto en un sentido inicialmente opuesto al del convenio número 29, en el caso CDH, Bernadette Faure v. Australia, de 23 de noviembre de 2005, ofrece una definición similar, marcada por el elemento degradante o deshumanizador. Concretamente, sostiene el citado comité que "el término ‘trabajo forzoso u obligatorio' comprende toda una gama de conductas que abarcan desde el trabajo impuesto a una persona por sanción penal, particularmente en condiciones especiales de coacción o explotación o inaceptables por otro motivo, hasta trabajos menos importantes en circunstancias en las que se amenaza con un castigo como sanción comparable en caso de no efectuarse el trabajo exigido".

El concepto se predica tanto de adultos como de menores de edad. Por tanto, resulta asimismo aplicable al trabajo de los menores al que se refiere el Convenio sobre las peores formas de trabajo infantil, 1999 (núm. 182), que afirma que "la expresión «las peores formas de trabajo infantil» abarca, entre otras cosas, «todas las formas de esclavitud o las prácticas análogas a la esclavitud, como la venta y la trata de niños, la servidumbre por deudas y la condición de siervo, y el trabajo forzoso u obligatorio, incluido el reclutamiento forzoso u obligatorio de niños para utilizarlos en conflictos armados»", según entiende la comisión de estudio de los convenios 29 y 105. Y, si bien existe un convenio específico en el que se tratan las peores formas de trabajo infantil, en la medida en que algunos Estados Miembros aún no lo han ratificado, el trabajo forzoso impuesto a los niños continuará siendo examinado en el marco del control de la aplicación del Convenio núm. 29.

\subsection{Elementos caracterizadores}

Por tanto, a la luz del primer convenio sobre trabajo forzoso de la OIT, para calificar como víctima de trabajo forzoso a un trabajador o a una trabajadora, estos deben estar imposibilitados de abandonar su trabajo a causa de una amenaza de castigo y deben realizar un trabajo en contra de su voluntad. Ello significa que deben concurrir dos elementos: a) falta de voluntad, y b) amenaza de castigo ${ }^{19}$.

a. Falta de voluntad. El trabajo ha de ser obligatorio. Si el consentimiento para trabajar o prestar servicios ha sido dado «bajo la amenaza de una pena cualquiera», los dos criterios se superponen: no hay «ofrecimiento voluntario» bajo la amenaza, entiende el Estudio 2007.

Según el mismo estudio, "una imposición externa o una coacción indirecta que coarte la libertad de un trabajador de «ofrecerse voluntariamente» puede resultar no sólo de una disposición

19 Para el examen minucioso de estos elementos, vid. Valverde Cano, Ana Belén: "It's all about control: el concepto de trabajos forzosos", cit, pp. 254 a 263. La citada autora analiza la cuestión a la luz de dos criterios: el de la carga desproporcionada y el de la naturaleza y volumen de trabajo, ambos manejados en la jurisprudencia del TEDH. 
APROXIMACIÓN LABORAL A LOS CONCEPTOS DE ESCLAVITUD, TRABAJO FORZOSO Y EXPLOTACIÓN LABORAL

dimanante de las autoridades, como un instrumento reglamentario, sino también de prácticas adoptadas por empleadores, como, por ejemplo, cuando los trabajadores migrantes son inducidos a engaño y, víctimas de falsas promesas, se les retienen los documentos de identidad o se les obliga a permanecer a disposición de un empleador" (o, como ocurre en el caso analizado por la sentencia del TEDH de 26 de julio de 2005, caso Siliadin contra Francia, se les hace creer así, porque las circunstancias especiales de vulnerabilidad de la víctima la hacían vulnerable a esta falsa amenaza). En cualquier caso, según sostiene el TEDH en la sentencia de 30 de marzo de 2017, caso Chowdury y otros contra Grecia, la validez del consentimiento debe ser evaluada a la luz de las circunstancias del caso.

En sí misma, la necesidad de trabajar por razones alimenticias no podría entenderse equivalente a esta falta de voluntad, pero el estudio general admite que sí podría ser pertinente sólo en concomitancia con otros factores respecto de los cuales el Estado y los empleadores pueden ser responsables. Ni tampoco la prestación obligatoria de un servicio propio de una profesión o de los requisitos de acceso a la misma, como sucede en el caso de la sentencia de 23 de noviembre de 1983, caso Van der Mussele contra Bélgica, respecto de la profesión de abogado (lo que incluiría la pasantía obligatoria o prácticas no remuneradas), porque, además de obligatoria, debe ser "injusta" u "opresiva" o su ejecución representar "realmente una carga" o, en otros términos, ser inútilmente penosa o vejatoria. Según entiende la sentencia citada, "podría considerarse en este caso como un servicio que ha de realizarse para acceder a una determinada profesión si impusiera una carga demasiado pesada o tuviera un carácter desproporcionado con las ventajas que comporta el ejercicio futuro de la profesión, que el servicio pudiera considerarse como no aceptado voluntariamente; esto podría ocurrir, por ejemplo, cuando la tarea a realizar no tuviera nada que ver con la profesión que se quiera desempeñar"20.

Finalmente, el inalienable derecho de los trabajadores a la libre elección del empleo conlleva calificar también de falta de voluntariedad en la prestación del trabajo aquel caso en el que se aceptó voluntariamente, pero en el que se permanece forzosamente, limitando la revocación del consentimiento libremente otorgado. Esto es, impedir al trabajador (a) que abandone el trabajo para el que previamente se obligó voluntariamente también sería un supuesto de trabajo forzoso. Y del mismo modo lo sería retenerle contra su voluntad cuando su contrato temporal ha expirado, violentando su libertad de abandonar el empleo. Ha de concurrir en todo caso coacción, sea esta jurídica, física o psicológica, concepto interpretado por el TEDH en su sentencia de 23 de noviembre de 1983, caso Van der Mussele contra Bélgica, que asocia "forzado" con coacción física o moral.

A las anteriores situaciones se asimila el empleo de menores de la edad mínima permitida por las legislaciones nacionales para acceder al empleo, en la medida en que el consentimiento

20 Es el caso también de la sentencia del TEDH de 18 de octubre de 2011, Caso Graziani-Weiss contra Austria, sobre otro supuesto de abogado nombrado de oficio como tutor de persona enferma mental para la gestión de los ingresos y la representación ante los tribunales y otras autoridades, entendido como servicio que forma parte de las obligaciones normales que debe prestar un abogado en ejercicio y en las que no se aprecia carga desproporcionada alguna. 
APROXIMACIÓN LABORAL A LOS CONCEPTOS DE ESCLAVITUD, TRABAJO FORZOSO Y EXPLOTACIÓN LABORAL

prestado no es válido, de acuerdo con el Convenio sobre la edad mínima 1973 (núm. 138), artículo 3.1, y el Convenio sobre las peores formas de trabajo infantil, 1999 (núm. 182), artículos 1 a 3.

b. Amenaza de castigo. La pena a la que se refiere el convenio, según el Estudio 2007, "podría revestir no solo la forma de una sanción penal, sino que podía tratarse también de la privación de cualquier derecho o ventaja". O, como indica el Informe Global de la OIT, El costo de la coacción (2009), amenazas de denuncia a la policía o a las autoridades de inmigración cuando la víctima se encuentra en una situación laboral ilegal (sentencia del TEDH de 26 de julio de 2005, caso Siliadin contra Francia), la confiscación de la documentación de identidad, o penas económicas.

El carácter forzoso u obligatorio implica que el individuo no puede abandonarlo so pena de sufrir una represalia, sin que sea determinado el alcance o gravedad de tal "pena" (aunque deba entenderse que será lo suficientemente grave como para funcionar de forma coercitiva sobre la persona), ni tampoco el destinatario de la misma, que podría no ser siquiera la propia persona forzada a trabajar. Según la interpretación auténtica que realiza la comisión del Estudio 2007, "esto puede ocurrir, por ejemplo, cuando las personas que se niegan a llevar a cabo un trabajo voluntario se exponen a perder determinados derechos, ventajas o privilegios, en una situación en la cual dichos derechos, privilegios u otras ventajas (tales como ascensos, traslados, acceso a un nuevo empleo, adquisición de determinados bienes de consumo, vivienda o participación en programas universitarios) dependen de los méritos acumulados e inscritos en el expediente laboral por los trabajadores". También lo sería cualquier otra que pueda implicar una desventaja, como considera el TEDH en la sentencia de 23 de noviembre de 1983, caso Van der Mussele contra Bélgica, en la que esta pena consiste en el rechazo de la colegiación del abogado en prácticas. En la sentencia del mismo tribunal, de 11 de octubre de 2012, caso C.N. contra Francia, se entiende por tal la devolución al país de origen de la víctima.

Esta "amenaza" cuesta de asimilar en el contexto de una relación laboral estándar, en la que la amenaza podría equiparse a la obligatoria realización de horas extraordinarias bajo el chantaje descrito, lo que, de acuerdo con las legislaciones nacionales europeas, y en particular la española, nunca podría calificarse como supuesto de trabajo forzoso, sino como abuso empresarial o ejercicio irregular de sus facultades directivas, tutelable dentro del marco contractual por la jurisdicción social. No obstante, la Comisión de estudio del convenio, en su Estudio 2007, se cuestionaba si determinadas prácticas no podrían ser asimilables al trabajo forzoso en la medida en que se produce una explotación de la vulnerabilidad del trabajador "amenazado con el despido, o forzado a trabajar más allá de la jornada ordinaria de trabajo para cumplir con metas de producción que le permitan alcanzar el salario mínimo, limita su libertad, sus derechos a rechazar trabajo impuesto bajo la amenaza de una pena".

Esta definición prescinde del modo, causas o circunstancias, que lleven al trabajo forzoso (aunque sí se describen en el Convenio sobre la abolición del trabajo forzoso número 105 de la OIT), para centrarse en los dos elementos señalados: que se realiza contra la voluntad del individuo que lo presta y bajo una amenaza de castigo o represalia. Por ello resulta compatible con la referencia 
APROXIMACIÓN LABORAL A LOS CONCEPTOS DE ESCLAVITUD, TRABAJO FORZOSO Y EXPLOTACIÓN LABORAL

a la "trata" que contiene el artículo 4 como vía para colocar a un individuo bajo esa posición de sumisión que implica el trabajo forzoso (y sinónimo de "comercio"), aunque, como se verá, la trata conlleva en sí un sometimiento a explotación que tampoco tiene carácter voluntario para la víctima y que conforma, por la unión de ambos elementos, el resultado o situación definido como tal.

El convenio número 105 utiliza como términos sinónimos los de "forzoso" y "obligatorio" en su artículo $1^{21}$ para mantener la definición anteriormente descrita. Pero no se refiere a la trata. Al contrario que el Protocolo de 2014 relativo al Convenio sobre el trabajo forzoso, 1930, adoptado en Ginebra, en la 103ª reunión CIT (11 de junio de 2014), y en vigor desde el 9 de noviembre de 2016, que recuerda que la definición de trabajo forzoso u obligatorio prevista en el artículo 2 del Convenio abarca el trabajo forzoso u obligatorio en todas sus formas y manifestaciones (y se aplica a todos los seres humanos sin distinción) y, en concreto, en su artículo 3 "reafirma la definición de trabajo forzoso u obligatorio contenida en el Convenio", refiriéndose a continuación explícitamente a la trata de personas con fines de trabajo forzoso u obligatorio. Pero es obvio que estas pueden graduarse en su gravedad desde un nivel muy bajo hasta formas muy graves.

Por otra parte, el concepto así definido no implica que la forma en la que se ejecute el trabajo sea en sí misma vejatoria, humillante, indigna (como sienta la Comisión de la OlT en su Estudio 2007, en las definiciones de la trata, la explotación de mano de obra como principal objetivo suele estar asociada a condiciones de trabajo particularmente duras y abusivas, o «condiciones de trabajo incompatibles con la dignidad humana») o bajo sumisión permanente, ni que la sujeción a dicho carácter forzoso tenga una duración específica en el tiempo. Que sea así lo demuestran las propias excepciones previstas en el convenio aludido cuando se refieren a servicios que se dispongan como obligatorios para los ciudadanos de un territorio por sus legítimos gobernantes.

\subsection{Exclusiones}

Asimismo, hay que considerar ciertas exclusiones o excepciones que el propio convenio entiende que quedarían fuera del ámbito de la prohibición del trabajo forzoso, siempre y cuando no constituyan casos de «movilización y utilización de la mano de obra con fines de fomento económico», al traspasar los límites delimitados por el artículo 2, apartado 2:

a. el cumplimiento del servicio militar obligatorio o análogo (siempre y cuando se trate de «un trabajo de carácter puramente militar» y no «como método de movilización y utilización de la mano de obra con fines de fomento económico» ${ }^{22}$ ),

21 Términos que se utilizan como sinónimos en otros instrumentos legales procedentes de la 0IT, como es el caso de la Declaración relativa a los principios y derechos fundamentales en el trabajo y su seguimiento, adoptada por la Conferencia Internacional del Trabajo en su octogésima sexta reunión, Ginebra, 18 de junio de 1998, artículo 2 b).

22 El TEDH aclara que esta prestación obligatoria no puede identificarse con la carrera militar, por lo que la adscripción forzosa a un trabajo tampoco estará incluida en la excepción (sentencia de 4 de junio de 2015, caso Chitos contra Grecia). 
APROXIMACIÓN LABORAL A LOS CONCEPTOS DE ESCLAVITUD, TRABAJO FORZOSO Y EXPLOTACIÓN LABORAL

b. las obligaciones cívicas normales de los ciudadanos de un país, sobre la base de una concepción de solidaridad social ${ }^{23}$ (con inclusión de los pequeños trabajos comunales en beneficio directo de la comunidad, pero también otras obligaciones cívicas como la integración en un jurado popular o las derivadas de procesos electorales); junto a estos, se citan los trabajos comunales (art. 2.2.e del Convenio);

c. Ios que se deriven de una condena pronunciada por sentencia judicial (de un Estado de Derecho), ya sea un trabajo penitenciario obligatorio o un trabajo exigido en virtud de la imposición de otros tipos de condenas, como una sentencia de trabajo comunitario (pero nunca la cesión o puesta a disposición de particulares, compañías o personas jurídicas de carácter privado, no consentidos por el recluso, tanto si los trabajos se realizan fuera del establecimiento penitenciario como si se ejecutan dentro de este en talleres de empresas privadas en el interior de las prisiones ${ }^{24}$ ), con exclusión de los impuestos a personas condenadas por sus opiniones o por haber participado en una huelga (ya que en estos casos el trabajo no cumple funciones de reinserción social, sino de represión por ideología, y constituye medio de coerción política, una de las formas que puede adoptar, según el propio convenio, el trabajo forzoso —artículo 1-), y de los Ilamados "trabajos forzados" en los que el trabajo forma parte de la propia sanción penal25;

d. o los trabajos que exijan circunstancias de fuerza mayor (guerra, siniestros o amenaza de siniestros y en todas las circunstancias que pongan en peligro o amenacen poner en peligro la vida o las condiciones normales de existencia de toda o parte de la población) ${ }^{26}$ y solo por el tiempo estrictamente necesario. No así los trabajos públicos de interés general o el servicio obligatorio con fines de desarrollo nacional ${ }^{27}$.

23 Sentencia del TEDH de 18 de octubre de 2011, Caso Graziani-Weiss contra Austria.

24 Abolición del trabajo forzoso, Estudio general de 1979, párr. 98, y Estudio general de 2007, cit., p. 28. La Memoria de la OIT sobre el trabajo penitenciario, vol. V, núm. 5, detalla estas condiciones. El Estudio 2007 se muestra más contundente al afirmar que no constituye trabajo forzoso el prestado en establecimientos penitenciarios por reclusos condenados por sentencia judicial "aun en el caso en que el trabajo se imponga a estas personas bajo la amenaza de sanciones y contra su voluntad" (op.cit., 82). Son de aplicación las reglas 96 a 103 de las reglas internacionales para el tratamiento de los internos, aprobadas el 17 de diciembre de 2015 en Viena por la Comisión de Naciones Unidas para la Prevención del Delito y la Justicia Penal (sentencia del TEDH de 21 de enero de 2016, caso L.E. contra Grecia). El TEDH entiende que no es exigible el alta en un sistema de la Seguridad social para aplicar la exclusión en la sentencia de 7 de julio de 2011, asunto Stummer contra Austria GS.

Como señala la comisión de estudio de la 0IT, las expresiones «trabajos forzados» (es decir, un tipo especifico de pena impuesta en virtud del derecho penal de algunos paises) y «trabajo forzoso» (utilizada en el Convenio) son consideradas en algunos idiomas como equivalentes o similares (El trabajo forzoso, Estudio general de 1968, párr. 86, y Abolición del trabajo forzoso, Estudio general de 1979). Y Estudio general de 2007, cit., p. 84.

27 Informe de la Comisión de Expertos en Aplicación de Convenios y Recomendaciones, Informe III (Parte IV), Conferencia Internacional del Trabajo, 46. ${ }^{a}$ reunión, Cinebra, 1962, Tercera parte: El trabajo forzoso. 
El Convenio sobre la abolición del trabajo forzoso de 1957 (número 105), de la OIT, adoptado en la 40ª reunión de la CIT de 25 de junio de 1957, no efectúa excepción alguna a la prohibición absoluta del trabajo forzoso u obligatorio, lo que no significa la derogación de la excepción, dado el carácter complementario de este convenio (incluso la comisión autora del Estudio 2007 insiste en que el mantenimiento transitorio y excepcional del trabajo forzoso para fines públicos admitido por el artículo 1.2 del convenio de 1929 debe entenderse transcurrido y, por tanto, perdido el vigor de tal disposición).

En el ámbito europeo, el Convenio Europeo de Derechos Humanos (1950) considera excluidos del concepto en su artículo 4.3: a) todo trabajo exigido normalmente a una persona privada de libertad en las condiciones previstas por el artículo 5 del Convenio, o durante su libertad condicional; b) todo servicio de carácter militar o, en el caso de objetores de conciencia en los países en que la objeción de conciencia sea reconocida como legítima, cualquier otro servicio sustitutivo del servicio militar obligatorio; c) todo servicio exigido cuando alguna emergencia o calamidad amenacen la vida o el bienestar de la comunidad; d) todo trabajo o servicio que forme parte de las obligaciones cívicas normales. Por tanto, se trata de la transcripción de las causas previstas en el convenio de la OIT. Mas adelante se tratará sobre la interpretación que el TEDH ha efectuado de este precepto y del concepto que en él se establece del "trabajo forzoso", al que denomina "forzado u obligatorio".

Y, en el ámbito americano, la Convención Americana sobre Derechos Humanos (San José de Costa Rica, 22 de noviembre de 1969) excluye en su artículo 6: a) los trabajos o servicios que se exijan normalmente de una persona recluida en cumplimiento de una sentencia o resolución formal dictada por la autoridad judicial competente (tales trabajos o servicios deberán realizarse bajo la vigilancia y control de las autoridades públicas, y los individuos que los efectúen no serán puestos a disposición de particulares, compañías o personas jurídicas de carácter privado); b) el servicio militar y, en los países donde se admite exención por razones de conciencia, el servicio nacional que la ley establezca en lugar de aquel; c) el servicio impuesto en casos de peligro o calamidad que amenace la existencia o el bienestar de la comunidad, y d) el trabajo o servicio que forme parte de las obligaciones cívicas normales. Como puede constatarse, ambos textos, a su vez inspirados en el convenio núm. 26 de la OIT, son prácticamente idénticos. Como en el caso anterior, también la Corte Interamericana de Derechos Humanos ha realizado su propia interpretación del concepto de trabajo forzoso.

\subsection{Finalidades del trabajo forzoso}

Pero, por otra parte, el Convenio sobre la abolición del trabajo forzoso número 105 de la OIT, de 1957, no prohíbe todas las formas de trabajo forzoso, exclusión de las excepciones previstas en el convenio núm. 29, sino que directamente considera como tales sólo a las enumeradas en el artículo 1. El convenio no incide sobre el concepto en sí, pero sí sobre la finalidad que pueda perseguir el sometimiento a trabajo forzoso u obligatorio, elemento que permite asimismo construir el concepto, que en realidad definen los casos en los que puede considerarse prohibido el trabajo forzoso (y admitido, por tanto, en los restantes).

Y así, su artículo 1 enumera cinco medios o formas que el mismo puede perseguir: como medio de coerción o de educación políticas o como castigo basado en razones políticas o ideológicas (por 
manifestar oposición ideológica al orden político, social o económico establecido), como método de movilización y utilización de la mano de obra con fines de fomento económico (aun temporal o excepcional) ${ }^{28}$, como medida de disciplina en el trabajo, como castigo por participación en huelgas (legales o en todo caso que no pongan en peligro la vida o la salud de las personas o que persigan una finalidad puramente política ${ }^{29}$ ), y como medida de discriminación racial, social, nacional o religiosa ${ }^{30}$.

Este matiz aleja si cabe más claramente el trabajo forzoso del concepto de esclavitud laboral o trata y parece acercarlo más a una situación de instrumentalidad transitoria, vinculada a regímenes políticos que emplean el trabajo forzoso como forma de doblegar ideologías políticas principalmente. Pero resulta aún más claro si se considera que, bajo los convenios 29 y 105, podría calificarse como trabajo forzoso todo aquel en el que el o la trabajadora no prestara su consentimiento para la continuación de la relación laboral, o que fuera obligado(a) a continuar en el puesto de trabajo como sanción a su abandono, según prevén algunas legislaciones nacionales para sus empleados públicos destinados a servicios esenciales para la comunidad ${ }^{31}$.

El convenio no se refiere explícitamente a otras formas surgidas con posterioridad a su aprobación, que sí son consideradas en el Estudio 2007, ya citado, como son: a) los trabajos de utilidad pública, que se consideran como una alternativa al encarcelamiento y que pueden incidir en la observancia del Convenio: b) la privatización de las cárceles y el trabajo penitenciario privatizado, que se entiende pueden estar de conformidad con el artículo 2, párrafo 1, siempre que tal trabajo sea realizado voluntariamente y sin amenazas o sanciones; c) el trabajo obligatorio como condición para percibir las prestaciones de desempleo ${ }^{32}$, y d) la imposición de horas extraordinarias de trabajo (bajo el miedo fundado a perder el empleo o no alcanzar el salario mínimo en sistemas salariales a rendimiento), propias de maquilas y plantaciones o de empleados públicos.

El convenio rechaza toda imposición obligatoria de trabajo o movilización obligatoria de mano de obra que se establezca por las autoridades públicas con fines de fomento económico, aunque reconoce la derogación de estas prácticas en la mayoría de los Estados miembros (párrafo 168 del Estudio 2007).

Según el párrafo 188 del Estudio 2007, la prohibición de dichas huelgas no se halla dentro del campo de aplicación del Convenio núm. 105.

30 La Comisión aclara en su Estudio 2007 que ello incluye el delito sancionado es común, pero resulta agravado o calificado con esta nota discriminatoria en su imposición (párrafo 190).

31 Estudio General 2007, párrafos 177 y 178. No podría entenderse asi el establecimiento de servicios mínimos en caso de huelga que puedan acordarse por el gobierno (v.g. caso español), por cuanto estos no se imponen como pena correctiva al abandono del trabajo, sino como medida pública para la cobertura de servicios mínimos esenciales para la comunidad. La Comisión entiende que sólo pueden considerarse servicios esenciales aquéllos cuya interrupción podría poner en peligro la vida, la seguridad o la salud de la persona en toda o parte de la población (párrafo 185 del estudio general). Los supuestos se describen por el Comité de Libertad Sindical del Consejo de Administración de la OIT en La libertad sindical, Recopilación de decisiones y principios del Comité de Liberad Sindical del Consejo de Administración de la OlT, Ginebra, Oficina Internacional del Trabajo, quinta edición (revisada), 2006.

Al respecto la Comisión afirma que, en la medida en que el trabajo exigido no corresponda a un «empleo conveniente», se estaría en presencia de una forma de trabajo forzoso, si bien el Comité Europeo de Derechos Sociales, en sus Conclusiones XVII-1 sobre el caso de Dinamarca (2004), subrayó la obligación de aceptar cualquier empleo, independientemente de su categoría ocupacional, precisamente con miras a brindarles la oportunidad de hallar un empleo adecuado acorde con sus preferencias, competencias y calificaciones. 


\section{ESCLAVITUD Y SERVIDUMBRE}

La Convención sobre la esclavitud, firmada en Ginebra por la Sociedad de Naciones el 25 de septiembre de 1926, define la esclavitud como "el estado o condición de un individuo sobre el cual se ejercitan los atributos del derecho de propiedad o alguno de ellos" (artículo 1) y la trata de esclavos como "todo acto de captura, adquisición o cesión de un individuo para venderle o cambiarlo; todo acto de cesión por venta o cambio de un esclavo adquirido para venderlo o cambiarlo y, en general, todo acto de comercio de transporte de esclavos" (artículo 2).

La Convención suplementaria sobre la abolición de la esclavitud, la trata de esclavos y las instituciones y prácticas análogas a la esclavitud (Ginebra, 7 de septiembre de 1956) define (apartado a) la "esclavitud", según lo previsto en el convenio de 1926, como "el estado o condición de las personas sobre las que se ejercen todos o parte de los poderes atribuidos al derecho de propiedad, y como "esclavo" a "toda persona en tal estado o condición". En el apartado b) se refiere a la expresión "persona de condición servil" para indicar "toda persona colocada en la condición o estado que resulta de alguna de las instituciones o prácticas mencionadas en el artículo 1 de la Convención".

Parece, pues, que la condición de servidumbre constituye un grado inferior en la sujeción personal que deriva de la cosificación de la persona como bien propiedad de un titular. La jurisprudencia del TEDH, admitiendo que no existe una definición expresa, entiende en las sentencias sobre los asuntos Seguin ${ }^{33}$ y Siliadin ${ }^{34}$ que esta «prohíbe una forma de negación de la libertad, particularmente grave» (y cita en tal sentido el informe de la Comisión en el asunto Van Droogenbroeck contra Bélgica de 9 de julio de 1980, serie B, vol. 44, pg. 30, aps. 78 a 80), y que engloba, «además de la obligación de proporcionar a otra persona ciertos servicios (...) la obligación para el «siervo» de vivir en la propiedad de otra persona y la imposibilidad de cambiar su condición». De ello resulta, entiende el tribunal, que la «servidumbre», tal y como la entiende el Convenio, se considera la obligación de prestar servicios bajo el imperio de la coacción y que debe vincularse a la noción de «esclavitud» que la precede ${ }^{35}$. No parece que esta definición se distinga del trabajo forzoso, sino que describa la condición en la que queda la persona sometida al mismo, si no fuera por el resto de circunstancias concurrentes en este caso conforman un resultado distinto y de mayor gravedad que la mera falta de voluntad y amenaza de pena (trabajo durante quince horas al día y siete días a la semana, no habiendo elegido trabajar para el empleador al que fue destinada, menor de edad y vulnerable por encontrarse sola y sin recursos en un país extranjero, sin alojamiento ni medio de vida fuera del do-

Sentencia del TEDH de 16 de abril de 2002, caso Seguin contra Francia (núm. 42400/98).

A lo que Lousada Arochena denomina "esclavitud de facto" como sinónimo de la servidumbre, apelando a la inexistencia de una definición legal del concepto de servidumbre, y al que an̂ade un perfil que califica de novedoso, como es la conceptuación de estas situaciones como forma de violencia de género (Lousada Arochena, J. Fernando: "Normativa internacional contra la explotación humana y laboral en el trabajo doméstico: La 0NU y la 0IT", cit. pp. 162 a 164). 
APROXIMACIÓN LABORAL A LOS CONCEPTOS DE ESCLAVITUD, TRABAJO FORZOSO Y EXPLOTACIÓN LABORAL

micilio de los empleadores, a merced total de los mismos, bajo confiscación de su documentación y promesa falsa de legalización de su situación, amenaza de denuncia a la policía, y sin permiso para salir de casa salvo para supuestos muy concretos relacionados con los servicios prestados, sin tiempo libre ni libertad de movimientos ${ }^{36}$ ).

Por otra parte, el TEDH introduce un elemento de distinción entre trabajo forzoso y servidumbre en su sentencia 30 de marzo de 2017 (caso Chowdury y otros contra Grecia), que estriba en la percepción de las víctimas respecto del carácter temporal o permanente e irreversible de su situación. Insiste el tribunal en que debe distinguirse claramente explotación en el sentido de trata, utilizando el término explotación de manera exclusivamente vinculada a la trata de personas.

La Corte Interamericana de Derechos Humanos, que afirma compartir criterio con el Tribunal Penal Internacional ad hoc para la ex-Yugoslavia, el Tribunal Especial para Sierra Leona, y la Corte de Justicia de la Comunidad Económica de África Occidental, analiza, in extenso, el concepto de propiedad en su sentencia de 20 octubre de 2016, caso trabajadores de la Hacienda Brasil Verde contra Brasil. Dicha sentencia contiene una explícita y prolija definición, que parte de dos elementos fundamentales para "definir una situación como esclavitud", que son el estado o condición de un individuo y el ejercicio de alguno de los atributos del derecho de propiedad, es decir, que el esclavizador ejerza poder o control sobre la persona esclavizada al punto de anular la personalidad de la víctima". La citada sentencia afirma que, "para determinar una situación como esclavitud en los días actuales, se deberá evaluar, con base en los siguientes elementos, la manifestación de los Ilamados "atributos del derecho de propiedad": a) restricción o control de la autonomía individual; b) pérdida o restricción de la libertad de movimiento de una persona; c) la obtención de un provecho por parte del perpetrador; d) la ausencia de consentimiento o de libre albedrío de la víctima, o su imposibilidad o irrelevancia debido a la amenaza de uso de la violencia u otras formas de coerción, el miedo de violencia, el engaño o las falsas promesas; e) el uso de violencia física o psicológica; f) la posición de vulnerabilidad de la víctima; g) la detención o cautiverio, i) la explotación" ${ }^{37}$.

Respecto de la servidumbre, la misma sentencia sostiene que, a tenor de la jurisprudencia de distintos tribunales internacionales y también del TEDH, constituye una forma análoga a la esclavitud, de lo que infiere que "la prohibición absoluta de la esclavitud tradicional y su interpretación han evolucionado de modo que también comprende determinadas formas análogas de ese fenómeno, el cual se manifiesta en los días actuales de diversas maneras, pero manteniendo determinadas características esenciales comunes a la esclavitud tradicional, como el ejercicio de control sobre

36 Sobre este tema, vid. Salcedo Beltrán, Ma del Carmen: "El trabajo doméstico en España: planteamientos y desafíos insoslayables frente a la "esclavitud moderna"'. Revista General de Derecho del Trabajo y de la Seguridad Social, núm. 55, 2020.

37 En la misma línea, Lousada Arochena (op.cit., p. 165). Para el citado autor, "la servidumbre doméstica no solo constituye una diferencia de trato entre quien la sufre respecto a quien no la sufre, también constituye una diferencia de estado que coloca a una persona en una situación de subordinación contraria a su dignidad por ser mujer o realizar un trabajo propio de mujeres", de suerte que la servidumbre doméstica constituye una forma de violencia de género. Sobre la gravedad del problema y recomendaciones para atajarlo, vid. Shahinian, Gulnara: "La servidumbre doméstica: un problema mundial de derechos humanos" - Informe de la Relatora Especial sobre las formas contemporáneas de esclavitud, documento A/HRC/15/20, en www.acnur.org. 
una persona mediante coacción física o psicológica de tal manera que implique la pérdida de su autonomía individual y la explotación contra su voluntad". Para concluir que "por lo tanto, la Corte Interamericana considera que la servidumbre es una forma análoga de esclavitud y debe recibir la misma protección y conlleva las mismas obligaciones que la esclavitud tradicional".

Para el Tribunal Penal Internacional ad hoc para la ex-Yugoslavia, los criterios para determinar la existencia de una situación de esclavitud o reducción a la servidumbre son similares: a) restricción o control de la autonomía individual, la libertad de elección o la libertad de movimiento de una persona; b) la obtención de un provecho por parte del perpetrador; c) la ausencia de consentimiento o de libre albedrío de la víctima, o su imposibilidad o irrelevancia debido a la amenaza de uso de la violencia u otras formas de coerción, el miedo de violencia, el engaño o las falsas promesas; d) el abuso de poder; e) la posición de vulnerabilidad de la víctima; f) la detención o cautiverio, y g) la opresión psicológica por las condiciones socio-económicas. Otros indicadores de esclavitud serían: h) la explotación; i) la exacción de trabajo o servicios forzosos u obligatorios, por lo general sin remuneración y ligados frecuentemente - aunque no necesariamente- a la penuria física, el sexo, la prostitución y la trata de personas. Como analiza la sentencia Hacienda Brasil para referirse a la doctrina del Tribunal Penal Internacional para la ex Yugoslavia, "lo importante actualmente no es la existencia de un título de propiedad sobre el esclavo, sino el ejercicio de poderes vinculados con la propiedad que se traducen en la destrucción o anulación de la personalidad jurídica del ser humano" (apartado 259).

Finalmente, el análisis de la jurisprudencia europea y latinoamericana arroja una inquietante doble perspectiva en el análisis de los casos que envuelven a mujeres en el trabajo doméstico forzoso, a menudo calificados como formas menores de trabajo coactivo, frente a los que se conceptúan como formas más graves ${ }^{38}$.

\section{TRATA}

Los diversos textos internacionales, ya citados, y también los nacionales, proclaman la abolición de la esclavitud, aunque no lo hacen de manera unánime y expresa todos los países, en algunos casos por considerar superado tanto el concepto como el riesgo (v.g. España y otros países de la Unión Europea), lo que conduce a que tampoco algunos códigos penales occidentales tipifiquen como delito la "esclavitud"39, pero sí la trata de personas, concepto heredero de la vieja esclavitud.

39 En el caso de España, se tipifican en el artículo 311 del Código penal (Ley Orgánica 10/1995, de 23 de noviembre, del Código Penal) el tráfico de mano de obra, mas no el sometimiento a esclavitud, y en el artículo 172 del mismo texto el delito de coacciones (compeler a otro a efectuar lo que no quiere), pero, de nuevo, el delito no se ajusta exactamente a la conducta que puede definirse como sometimiento a esclavitud. 
APROXIMACIÓN LABORAL A LOS CONCEPTOS DE ESCLAVITUD, TRABAJO FORZOSO Y EXPLOTACIÓN LABORAL

El Convenio para la represión de la trata de personas y de la explotación de la prostitución ajena, adoptado por la Asamblea General en su resolución 317 (IV) de 2 de diciembre de 1949, se centra en la trata orientada a la prostitución, aunque no orbita alrededor de su carácter forzoso, por entender que toda explotación de la prostitución constituye trata ${ }^{40}$. El viejo convenio de Naciones Unidas no enfatizaba, pues, el carácter forzoso, sino simplemente la participación en la explotación sexual de una persona. El artículo 17 vincula la trata de personas (para fines de explotación sexual) a la emigración, asumiendo que la trata lo es por definición de personas extranjeras. La explotación sexual se contextualiza en el mercado de trabajo, en el artículo 20, al dirigir a las agencias de colocación su mirada inspectora con el fin de "impedir que las personas que buscan trabajo, en especial las mujeres y los niños, se expongan al peligro de la prostitución".

El concepto de trata de personas, que parece haber robado su protagonismo a la esclavitud por su crecimiento y actualidad mundial, no contaba con una definición unívoca hasta el Protocolo para prevenir, reprimir y sancionar la trata de personas, especialmente mujeres y niños (Palermo, 2000), que complementa la Convención de las Naciones Unidas contra la Delincuencia Organizada Transnacional (hecha en Nueva York el 15 de noviembre de 2000, resolución A/RES/55/25.

En su artículo 3 a) el convenio sienta la definición universal del concepto de "trata de personas", entendiendo por tal "la captación, el transporte, el traslado, la acogida o la recepción de personas, recurriendo a la amenaza o al uso de la fuerza u otras formas de coacción, al rapto, al fraude, al engaño, al abuso de poder o de una situación de vulnerabilidad o a la concesión o recepción de pagos o beneficios para obtener el consentimiento de una persona que tenga autoridad sobre otra, con fines de explotación. Esa explotación incluirá, como mínimo, la explotación de la prostitución ajena u otras formas de explotación sexual, los trabajos o servicios forzados, la esclavitud o las prácticas análogas a la esclavitud, la servidumbre o la extracción de órganos". La Comisión de la OIT, en su Estudio 2007, incide en que, en las definiciones de la trata, la explotación de mano de obra como principal objetivo suele estar asociada a condiciones de trabajo particularmente duras y abusivas, o «condiciones de trabajo incompatibles con la dignidad humana». Por tanto, se trata de un concepto que comporta un plus sobre el trabajo forzoso, que no necesariamente implica trato indigno.

Y ello es así porque, según clarifica la Oficina de las Naciones Unidas contra la Droga y el Delito (UNODC), guardián de la Convención contra la Delincuencia Organizada Transnacional y sus protocolos, se buscó de propósito esta unidad conceptual de tres elementos indisolubles: la acción (captación...), los medios (la amenaza o el uso de la fuerza u otras formas de coacción...), y el fin de explotación. Razón por la cual el protocolo no define ninguna otra conducta distinta a la de trata, ni tipifica otras conductas integrantes de la definición, v.g. la explotación de la prostitución, sin perjuicio de las opciones por las que se inclinen las legislaciones nacionales.

40 Marin de Espinosa Ceballos, Elena Blanca: "Lucrarse explotando la prostitución ajena, aún con el consentimiento: ¿Cabe el reconocimiento de la prostitución consentida como una relación laboral?", en AA.VV. (Pedro Mercado Pacheco, María Inmaculada Ramos Tapia; Esteban Juan Pérez Alonso, Sofía Olarte Encabo, dirs.): Formas contemporáneas de esclavitud y derechos humanos en clave de globalización, género y trata de personas, Tirant lo Blanch, 2020, pp. 695-719. 
APROXIMACIÓN LABORAL A LOS CONCEPTOS DE ESCLAVITUD, TRABAJO FORZOSO Y EXPLOTACIÓN LABORAL

Para la Convención del Consejo de Europa sobre la acción contra el tráfico de seres humanos (Varsovia, 2005), "la expresión «trata de seres humanos» designa la contratación, el transporte, el traslado, el alojamiento o la acogida de personas mediante amenazas de recurrir a la fuerza, recurso a la fuerza o cualquier otra forma de obligación, mediante rapto, fraude, engaño, abuso de autoridad o de una situación de vulnerabilidad o mediante la oferta o la aceptación de pagos o ventajas para obtener el consentimiento de una persona que tenga autoridad sobre otra con fines de explotación. La explotación incluirá, como mínimo, la explotación de la prostitución ajena o bien otras formas de explotación sexual, el trabajo o los servicios forzados, la esclavitud o prácticas similares a la esclavitud, la servidumbre o la extracción de órganos". En cambio, el Convenio Europeo de Derechos Humanos no se refiere a la trata, limitándose a declarar el derecho a no ser sometido a esclavitud o a servidumbre.

La diferencia entre ambas definiciones (Palermo/Consejo de Europa) es prácticamente nula: captación / contratación; recepción /alojamiento; poder /autoridad; y concesión o recepción de pagos o beneficios /aceptación de pagos o ventajas, respectivamente, mientras que la directiva incorpora un nuevo matiz: el "intercambio o la transferencia de control sobre estas personas", a cuenta de esa persona que posea el control sobre la víctima.

Como el código penal español, en ambos casos se citan por separado trabajos forzados y prostitución y otras formas de explotación sexual. Sin embargo, el elemento común es la explotación: que la acción descrita se realice "con fines de explotación", acción que consuma la perpetración del delito ${ }^{41}$. Se entiende que hablamos de explotación económica, es decir, dirigida a obtener un beneficio. En todos los casos el carácter forzoso de este sometimiento a la explotación deriva de un consentimiento viciado, por haberse obtenido mediante amenaza, uso de la fuerza, coacción, rapto, fraude, engaño, chantaje, abuso de poder o de una situación de vulnerabilidad, o por minoría de edad.

Finalmente, en el ámbito de la Unión Europea, la Directiva 2011/36, de 5 de abril, sobre la prevención contra la trata de seres humanos y la lucha contra este fenómeno, así como la protección de las víctimas, define en su artículo 2.1 la trata como "la captación, el transporte, el traslado, la acogida - la recepción de personas, incluido el intercambio o la transferencia de control sobre estas personas, mediante la amenaza o el uso de la fuerza u otras formas de coacción, el rapto, el fraude, el engaño, el abuso de poder o de una situación de vulnerabilidad, o mediante la entrega o recepción de pagos o beneficios para lograr el consentimiento de una persona que posea el control sobre otra persona, con el fin de explotarla". Y considera que "la explotación incluirá, como mínimo, la explotación de la prostitución ajena, u otras formas de explotación sexual".

la OIT también se ha pronunciado sobre este concepto. En su Estudio 2007 efectúa un análisis de las relaciones entre trata y trabajo forzoso, a tenor del cual un componente esencial de la definición de la trata es su finalidad, es decir la explotación, que incluye especificamente el trabajo o los ser-

41 Según la sentencia del Tribunal Supremo (Sala Penal) núm. 270/2016, de 5 de abril, siendo la trata un delito de actividad, la explotación sexual constituiría una fase de agotamiento del delito, sin que el delito medio absorba toda la gravedad de la conducta realizada. 
APROXIMACIÓN LABORAL A LOS CONCEPTOS DE ESCLAVITUD, TRABAJO FORZOSO Y EXPLOTACIÓN LABORAL

vicios forzosos, la esclavitud o las prácticas análogas a la esclavitud, la servidumbre y las distintas formas de explotación sexual. La noción de explotación del trabajo contenida en esta definición permite establecer la relación entre el Protocolo de Palermo y el Convenio núm. 29, y dejar claro que la trata de seres humanos con fines de explotación encaja en la definición del trabajo forzoso u obligatorio establecida en el párrafo 1 del artículo 2 del Convenio. Para concluir que "esta concordancia facilita la labor de aplicación de ambos instrumentos a escala nacional".

El mismo estudio subraya que el trabajo forzoso puede perseguir un fin económico, pero también puede instrumentalizarse para obtener un fin coercitivo o un fin ideológico (cuando se impone como pena en delitos de naturaleza ideológica o política), siendo objetivo principal del convenio la lucha contra las modalidades de trabajo forzoso con fines económicos. Pero igualmente sostiene que "el tenor del artículo 3 del Protocolo da a entender que la trata de personas con el fin de someterlas a trabajo forzoso es apenas una forma de explotación relacionada con el trabajo, junto con la esclavitud o las prácticas análogas a la esclavitud, o la servidumbre". Mientras que la convención suplementaria 105 de la OIT permite distinguir entre explotación de la persona y explotación del trabajo de la persona en su apartado d) ("...con el propósito de que se explote la persona o el trabajo del niño o del joven"), lo que parece sentar la distinción entre esclavitud y trabajo forzoso ("explotación laboral"), para considerar la última como una "práctica análoga a la esclavitud".

Elemento común, por tanto, es que medie el fin de la explotación del trabajo ajeno, sexual o no, con fines económicos.

En el caso de la trata, deben darse dos elementos adicionales con respecto a inmigración ilegal: una forma de captación indebida, con violencia, intimidación, engaño, abuso de poder o pago de precio; y un propósito de explotación, principalmente sexual. Por lo que la trata se define por la captación de la persona para someterla a trabajo forzado o a explotación sexual, una unidad de acción que funde captación con sometimiento a condiciones de esclavitud. Lo que significa que el concepto y delito de tráfico de mano de obra se reserva para la mera introducción de trabajadores extranjeros dentro del país con vulneración de las normas sobre emigración (desde que el código penal español se reformara en el año 2010 para efectuar esta división), lo que queda lejos del fenómeno que se analiza y lo sitúa en la esfera de ilícitos contra el régimen administrativo de fronteras y flujos migratorios, cuando el trato al que se somete a la persona no incide sobre su dignidad y libertades ${ }^{42}$.

42 El Tribunal Supremo español entiende que "solo en los supuestos agravados de puesta en peligro de la vida o la integridad del inmigrante, se atiende además al bien jurídico pregonado en la rúbrica del título, como 'Delitos contra los derechos de los ciudadanos extranjeros"' (sentencia núm. 188/2016, de 4 de marzo). 


\section{EXPLOTACIÓN}

\subsection{Explotación del trabajo y explotación de la persona}

La convención suplementaria 105 de la OIT marca una diferencia entre explotación de la persona y explotación del trabajo de la persona en su apartado d) ("...con el propósito de que se explote la persona o el trabajo del niño o del joven"). Esto puede llevar a ver una distinción entre esclavitud y trabajo forzoso (con el que identificar la "explotación laboral").

Por su parte, según destaca el Informe Global de la OIT 2009, el Protocolo de Palermo, en su artículo 3, da a entender que la trata de personas con el fin de someterlas a trabajo forzoso es una modalidad de explotación relacionada con el trabajo, junto con la esclavitud o las prácticas análogas a la esclavitud, o la servidumbre. Sin embargo, no se refieren como concepto autónomo a la explotación, sino como finalidad perseguida por la trata ${ }^{43}$.

El Derecho español sí regula, no obstante, una figura que, aunque no se denomina explícitamente como tal, sí puede considerarse una figura que tipifica la explotación laboral. Se trata de un supuesto que puede englobarse dentro de un conjunto de fenómenos para-esclavistas que, tanto su tipificación legal como en su configuración conceptual, quedan fuera del concepto de esclavitud, excluyendo también de este concepto el tráfico ilegal de mano de obra, no destinada a explotación de orden esclavista, sino relacionada con la cesión ilegal de trabajadores fuera del marco de contratación legal ${ }^{44}$, que, de ser extranjeros, inciden en el control de fronteras y flujos migratorios y, por tanto, en la entrada irregular en territorio nacional (concretamente la conducta tipificada es la de emplear a súbditos extranjeros sin permiso de trabajo en condiciones que perjudiquen, supriman o restrinjan los derechos que tuviesen reconocidos por disposiciones legales, convenios colectivos o contrato individual).

43 En tal sentido, López Rodriguez y Arrieta Idiakez contextualizan el concepto de "explotación laboral" en el contexto de la trata de seres humanos (López Rodríguez, Josune, y Arrieta Idiakez, Francisco Javier: "La trata de seres humanos con fines de explotación laboral en la legislación española", ICADE. Revista cuatrimestral de las Facultades de Derecho y Ciencias Económicas y Empresariales, núm. 107, 2019, D0I: https://doi.org/10.14422/icade. i107.y2019.002, pp. 2 y 3).

Como se afirma en la Sentencia del Tribunal Superior de Justicia de Madrid núm. 966/2015, de 4 de diciembre, "en el fenómeno jurídico de la cesión de trabajadores aparece, indefectiblemente, una relación interempresarial por virtud de la que una empresa proporciona a otra mano de obra, obteniendo de este tráfico o intermediación un beneficio económico, que es la justificación o razón de ser de la entidad intermediadora. Pero si el trabajo no es una mercancía el legislador debe contemplar con precaución la intermediación por las reminiscencias históricas de la esclavitud y porque la persona es portadora de derechos y valores fundamentales que es preciso tutelar en todo caso". En sentencias anteriores del mismo tribunal, entre ellas las núm. $570 / 2011$, de 17 de junio, núm. 637/2011, de 1 de julio, y núm. 605/2014, de 4 julio, también se vincula trabajo-mercancía y esclavitud en los mismos términos de riesgo derivado de la intermediación empresarial. 


\subsection{Imposición de condiciones laborales abusivas y trabajo decente}

¿Y dónde entra la explotación laboral? La respuesta es que en todas y en ninguna. En todas forma parte de los rasgos de la figura, pero solo en un caso es el elemento determinante. Y este caso es el que puede tener tintes puramente laborales o bien incluso penales, como ocurre en el Código penal español, que tipifica la explotación laboral en el artículo 311.1, al regular la aplicación de condiciones ilegales como delito (el precepto se refiere al sometimiento del trabajador a condiciones laborales perjudiciales, o que supriman o restrinjan sus derechos).

Como advierte la OIT en su informe global de 2009, se trata de un concepto que no cuenta con precedentes legislativos, ni internacionales ni nacionales. Su convención suplementaria 105 marca una diferencia entre explotación de la persona y explotación del trabajo de la persona en su apartado d), lo que permite atisbar una distinción entre esclavitud y trabajo forzoso (con el que identificar la "explotación laboral").

Y también el Protocolo de Palermo en su artículo 3 sugiere que la trata de personas con el fin de someterlas a trabajo forzoso constituye una modalidad de explotación relacionada con el trabajo, junto con la esclavitud o las prácticas análogas a la esclavitud, o la servidumbre. Sin embargo, no se refieren como concepto autónomo a la explotación, más allá de aludir a la finalidad perseguida por la trata.

En esta escala de gravedades y responsabilidades, el concepto de esclavitud laboral se va diluyendo hasta llegar al escalón más bajo, el del uso irregular de las facultades de dirección empresarial, y en este proceso se encuentra con la actuación de los poderes públicos en distintos niveles coercitivos: penal para la explotación laboral ejercida mediante engaño o abuso de situación de necesidad, con o sin violencia o intimidación (en cuyo caso la pena sería la superior en grado); administrativa para la que no reúna estas características o gravedad, por lo que no sería necesario que concurrieran ni engaño, ni abuso de situación de necesidad, ni violencia o intimidación; y contractual-laboral para el "simple" ejercicio irregular de las facultades directivas del empresario, concurrente o no con la aplicación de condiciones discriminatorias (que puedan determinar distintos resultados, ya sea la nulidad de las decisiones empresariales que conlleven tal irregularidad, y la reposición del trabajador a sus condiciones anteriores o a las que deberían haberse aplicado, la indemnización del daño, o hasta el derecho de rescisión indemnizada del contrato para el trabajador). Pero en todos ellos el elemento común es que no existe referencia alguna al sometimiento obligado a trabajo forzoso ni tampoco a esclavitud.

La frontera entre condiciones laborales abusivas y (delito de) explotación laboral deviene entonces más difusa, a lo que contribuye la legislación más o menos liberal y la coyuntura económica. Por ello, el momento histórico que se vive actualmente en la economía capitalista y en particular en la Unión Europea, y más concretamente la crisis económica vivida en España en el último decenio, han tensado esa línea divisoria, llevando a toda clase de consideraciones, algunas hiperbólicas, sobre el estado de explotación laboral en el que se encuentra buena parte del mercado laboral español. Incluso las organizaciones sindicales recurren al término de "explotación laboral" para definir este nuevo statu quo de la clase trabajadora (el 15 de mayo de 2010 el sindicato español Unión 
APROXIMACIÓN LABORAL A LOS CONCEPTOS DE ESCLAVITUD, TRABAJO FORZOSO Y EXPLOTACIÓN LABORAL

General de Trabajadores, UGT, afirmaba que "la explotación laboral se concibe como la nueva forma de esclavitud del siglo XXI", en el marco de la campaña "Por un trabajo digno, contra la explotación laboral", campaña que dio paso en el año 2017 a la campaña "No a las multiservicios", dedicada a la lucha contra "la explotación laboral" en las empresas multiservicios, donde, afirman literalmente sus promotores, "la gran mayoría de los trabajadores de estas empresas tiene un salario de 10.000 euros anuales; tienen jornadas con un número elevado de horas de trabajo y con condiciones de esclavitud o semi esclavitud").

Sin embargo, se trata de un uso impropio o reivindicativo del concepto "explotación laboral" como sinónimo de "precariedad laboral". Tanto es así que las propias campañas sindicales utilizan indistintamente ambos términos, explotación y precariedad laboral, como es el caso de la campaña de 2017, de UGT, Precario NO, gracias, contra las prácticas laborales de las empresas multiservicios en España, caracterizadas por la aplicación de salarios bajos y jornadas largas. Las denuncias sindicales apuntan a empresas multiservicios que ofrecen salarios inferiores a los previstos en el convenio colectivo aplicable a la empresa cliente o principal, por la vía de celebrar convenios de empresa (la empresa auxiliar), en los que el salario pactado es el mínimo legalmente establecido (el salario mínimo interprofesional). Se puede apreciar que, en esta, como en otras similares, se tiende a banalizar el concepto de explotación laboral para incluir situaciones definibles como "precariedad" o "precarización laboral", que, aunque lejanas del "trabajo decente", no pueden identificarse con la explotación laboral si entendemos esta como imposición de condiciones de trabajo ilegales. Como indica el Informe Global de la OIT, El costo de la coacción (2009) ${ }^{45}$, el trabajo forzoso constituye una grave violación de los derechos humanos y una restricción de la libertad de la persona, que no se puede confundir con la precariedad en el trabajo.

Lo cierto es que el recurso a la expresión "explotación laboral" se ha extendido, alejándose de las conductas tipificadas en el código penal o en los convenios internacionales, para englobar situaciones abusivas o imposición de condiciones laborales peyorativas o precarias para los trabajadores, aunque ello se haya producido en el contexto de una legislación que lo autoriza y, por tanto, deslegitimando su consideración de "imposición de condiciones laborales perjudiciales, o que supriman o restrinjan los derechos de los trabajadores" así establecidos legal o convencionalmente, puesto que el marco legal y derivadamente convencional también ha cambiado. Por acción de la legislación laboral, el ámbito de los derechos a condiciones laborales no perjudiciales... ha experimentado una expansión, así como una contracción el de las condiciones laborales perjudiciales, a las que se refiere el código penal. En suma, la legislación laboral neoliberal, nacida de las restricciones económicas impuestas por los mercados internacionales, y, en el contexto europeo, por las instituciones de la Unión Europea a cuenta de la recesión económica, ha alterado las fronteras entre ambos conceptos por expansión del concepto neoliberal de la "flexibilidad laboral", pero también ha permitido una difusión creciente de la creencia social en la existencia extendida de una situación de explotación laboral consentida, lo cual no ha contribuido tampoco a la clarificación de conceptos.

45 OIT: Informe Global de la 0IT, El costo de la coacción, 5 de diciembre de 2009, cit., p.7. 
APROXIMACIÓN LABORAL A LOS CONCEPTOS DE ESCLAVITUD, TRABAJO FORZOSO Y EXPLOTACIÓN LABORAL

Sin embargo, en términos legales, la explotación laboral puede tener una dimensión penal, la que viene determinada en el caso español por el artículo 311.1 del código penal, y una dimensión social, donde cabría encajar el uso irregular de las facultades directivas en sus formas más graves, las que suponen imposición de condiciones de trabajo abusivas. Ninguna respuesta específica puede obtenerse por parte de la ley si no se trata de sancionar los casos dolosos más graves por aplicación del art. 311.1 del código penal, y los que no alcanzan tal gravedad por aplicación de la Ley de infracciones y sanciones en el orden social (LISOS). La explotación laboral pasa a ser un modo informal de referirse a la liberalización de las relaciones laborales y a la ampliación de las facultades empresariales. Pero sin olvidar que estamos ante formas legales de restringir los derechos laborales en todo caso, mientras que la ley está diseñada para considerar como explotación las formas ilegales. Podría recurrirse, para salvar este equívoco, a la doble terminología "explotación con fines laborales" (o económicos) y "explotación laboral", para delimitar en este último caso la imposición de condiciones abusivas, aun cuando estas no sean estrictamente ilegales.

Sin perjuicio de ello, el incumplimiento de la legislación laboral, siendo sancionable administrativamente como infracción laboral, podría declararse, en un plano conceptual, supuesto de explotación laboral como sinónimo de graves incumplimientos de la normativa laboral.

Esto nos lleva a una encrucijada paradigmática: la explotación laboral puede ser un fenómeno tanto legal como ilegal, pero en todo caso abusiva, ya sea por las condiciones laborales impuestas, ya sea por la situación de vulnerabilidad social quien las padece (en el primer caso auspiciada por la grave recesión económica, generadora de regresión social en derechos laborales y del crecimiento del número de trabajadores pobres, concepto que se está imponiendo para definir a una amplia masa de ciudadanos sometidos a un alto nivel de precarización laboral).

Pero no sería explotación, en cualquier caso, la imposición de condiciones precarias establecidas o permitidas por la ley. Si bien no es menos cierto que, como denuncia el sindicato UGT, el elemento de vulnerabilidad propio de la explotación puede estar presente también en estos casos de paraexplotación, cuando se trata de trabajadores extranjeros, por la interposición de factores de riesgo como son el temor a la expulsión del país, la necesidad del trabajo para la subsistencia, la ausencia de redes familiares y sociales, el desconocimiento de sus derechos, y su situación administrativa irregular o ausencia de representación sindical. Elementos todos ellos que contribuyen a que el trabajador extranjero se preste con menor resistencia a la degradación de sus condiciones laborales.

\section{SITUACIONES LABORALES FRONTERIZAS}

Algunos supuestos se encuentran en una zona difusa entre los conceptos analizados. Así, las condiciones laborales abusivas, los tratos degradantes en el trabajo, o la imposición de trabajos y servicios en determinados contextos obligatorios. En este último caso, la Comisión de Expertos de la OIT ha 
manifestado que no siempre resulta fácil establecer la distinción entre formación y empleo, ya que un programa de formación profesional puede entrañar la imposición de trabajos o servicios en el sentido de la definición de «trabajo forzoso u obligatorio» (estudios generales de 1968, de 1979, o de 2007), lo que exige analizar todos los elementos del supuesto en cuestión para valorar la posible concurrencia de ese carácter forzoso ${ }^{46}$.

\subsection{Condiciones laborales abusivas frente a condiciones laborales ilegales}

No toda imposición de condiciones laborales abusivas puede equipararse a un régimen de trabajo coactivo o de explotación, conforme ya se ha analizado, al amparo de textos normativos internacionales o nacionales. Como se exponía anteriormente, quizás podría salvarse esta confusión terminológica o conceptual recurriendo al uso de los términos "explotación con fines laborales" (o económicos) y "explotación laboral", reservado este último para describir la imposición de condiciones abusivas, aun cuando estas no sean estrictamente ilegales, y el primero de ellos para definir la explotación laboral ejercita mediante engaño o abuso de situación de necesidad, con o sin violencia o intimidación.

En este marco conceptual, la imposición de condiciones abusivas puede traspasar la frontera trazada con la explotación cuando tales condiciones son claramente ilegales, es decir, vulneren la legalidad vigente, conformada por la conjunción de la norma y el convenio colectivo, y complementado por el contrato de trabajo como fuente reguladora de la relación laboral ${ }^{47}$. Pero quedan en una frontera difusa, en tierra de nadie, los supuestos "desregulados" o sin regulación, aquellos ámbitos donde el empleo no está estructurado, y el subempleo no se ajusta a ninguna norma en particular, rigiéndose únicamente por los elementos mínimos conformados por el referente salarial mínimo legal (el salario mínimo interprofesional) y el cumplimiento de unos parámetros legales mínimos. Es obvio que el incumplimiento de los parámetros legales determinados por la legislación laboral (en España la Ley del Estatuto de los Trabajadores) convierte el supuesto en un caso de imposición de condiciones de trabajo ilegales, pero también es cierto que a efectos penales, no todo incumplimiento constituye delito, sino los más graves; a efectos administrativos, puede considerarse infracción el incumplimiento, grave o no, de alguno de esos parámetros; $y$, a efectos laborales, cualquier incumplimiento de la legislación laboral determina una respuesta legal de censura, condena y tutela; pero en todos los casos resultará determinante el grado de incumplimiento y el alcance de este, ya que, si solo afecta a alguna o algunas condiciones de trabajo, se podrá calificar de abuso empresarial, pero únicamente los casos más graves podrán constituir explotación laboral.

46 Para la doctrina internacional, la clave se encuentra en el "continuum" de la explotación. Vid. al respecto Valverde Cano (op.cit., p. 271), con cita de Skrivankova (Skrivankova, Klara: Between decent work and forced labour: examining the continuum of exploitation, 2010, pp. 17 y ss.), quien afirma que el elemento que permite distinguir al trabajo forzoso de otras figuras limítrofes es el control continuado sobre la persona sometida al trabajo hipotéticamente forzoso. La autora utiliza una herramienta de medición que permite detectar y calificar cada situación bajo su concepto exacto, ya que, afirma, "la diferencia entre ellas es una cuestión de control y sometimiento, hasta llegar al extremo de la completa instrumentalización de la persona", para separar el grado de gravedad del elemento de control en la calificación de las distintas figuras analizadas.

47 A este contrato se refiere Salas Porras como "contrato de esclavo" (Salas Porras, María: "cit., p. 39). 
APROXIMACIÓN LABORAL A LOS CONCEPTOS DE ESCLAVITUD, TRABAJO FORZOSO Y EXPLOTACIÓN LABORAL

Sea como sea, no es el derecho del trabajo el que da respuesta a estos casos, sino únicamente a los que constituyen explotación, por más que retóricamente se empleen los términos de condiciones similares a la esclavitud o de semi esclavitud en ciertas resoluciones judiciales del ámbito social.

\subsection{Integridad moral y trato degradante}

En las fronteras entre el trato degradante y humillante grave y la esclavitud o sometimiento a condición servil se encuentran los casos más graves de violación del derecho a la integridad moral. No parece que esta situación a priori deba calificarse de esclavitud, y, de hecho, contamos con figuras jurídicas para calificarlo, penalizarlo y protegerlo: el acoso y la protección de la integridad moral (así como los delitos contra la integridad moral). Sin embargo, en algunas ocasiones se desliza en los tribunales españoles una alusión a la condición de servidumbre y esclavitud, tanto para trazar la separación entre estas y la vulneración del derecho a la integridad moral, como para recordar el avance que la civilización Ilamada occidental ha supuesto en la superación de aquellos estadios degradantes para los trabajadores.

En esta línea, las sentencias del Tribunal Superior de Justicia del País Vasco núm. 1737/2002, de 9 de julio, o la núm. 1419/2004, de 6 de julio, afirman literalmente que "cualquier iter sociológico nos Ileva a la superación de las relaciones primitivas, de esclavitud y feudales, para introducirnos en la actual de la civilización industrial. Esta época en que nos encontramos implica una vinculación de la persona a los medios, del sujeto y los instrumentos, desde las llamadas relaciones de dominación, para los críticos, del capital, y para los funcionalistas de la actividad. Sea cual sea, lo cierto es que en la concepción occidental el trabajador ante todo es persona, y cualquier relación que se establezca con él parte de este prius indisponible, de tal manera que cualquier hegemonía, predominio o prevalencia se contempla dentro de los simples y secundarios parámetros de organización en el trabajo, teniendo en cuenta que este no es un fin en sí mismo, y por ello, menos todavía, el sujeto que lo realiza". Citando la sentencia del Tribunal Constitucional de 27 de octubre de 2003, la anterior resolución afirma que este tribunal "se ha decantado por un respeto a un mínimo invulnerable que todo estatuto jurídico debe asegurar, de modo que las limitaciones que se impongan en el disfrute de los derechos individuales no conlleven un desprecio para la estima que cualquier ser humano merece como persona. Este respeto a la persona y a su vida privada implica el que no se pueda reducir al sujeto trabajador a un mero factor de producción, y negar su libertad, así como el despliegue de la personalidad en todo momento". Es preciso recordar que estas conductas pueden ser sancionables incluso penalmente, pero que no pueden confundirse en modo alguno con una situación de esclavitud ni de trabajo forzoso, ni siquiera con el sometimiento a condiciones de trabajo que perjudiquen, supriman o restrinjan los derechos legales, convencionales o contractuales (en el sentido del artículo 311.2 del Código penal).

Siendo escasos los supuestos en los que los tribunales españoles del orden social de la jurisdicción se pronuncian al respecto de hipotéticos casos de esclavitud, resulta destacable la sentencia del Tribunal Superior de Justicia de Asturias núm. 3194/2003, de 17 de octubre, pues equipara la falta de libertad que caracteriza al trabajo forzoso con la esclavitud, afirmando que el trabajador (perito tasador) «si no pudiese negarse a realizar el trabajo o encargo, en este caso una peritación, sería una 
relación forzosa y, por tanto, de esclavitud». También por la peculiaridad del caso puede citarse la sentencia del Tribunal Superior de Justicia de Castilla y León (sala social de Valladolid) de 12 de mayo de 2016, núm. 886/2016, en la que se declara improcedente el despido de la trabajadora que atribuye al empresario la condición de "negrero" y de "explotador". Como tercer y último ejemplo de este (seguramente afortunada) desierto jurisprudencial y judicial, se alude a la esclavitud en la sentencia del Juzgado de lo Social núm. 2 de Albacete, de 2 de octubre de 2001, dictada en el procedimiento núm. 729/2000, sobre un ama de cría en la cuna de un hospital, en la que la juzgadora entiende que "una vez abolida la esclavitud con prohibición de todo tipo de prestaciones corporales a cambio de precio, es claro que la función de amamantar a los bebés que no son propios solo puede serlo por benevolencia, como así sucedió".

Pero lo cierto es que la mayor parte de la jurisprudencia se ocupa de la explotación sexual relacionada con la trata de mujeres. Muy pocos son los casos en los que se abordan situaciones de explotación económica de la fuerza de trabajo de la víctima que no tengan que ver con el suculento negocio del sexo, aunque en la mayor parte de los supuestos la captación se produce bajo promesa de empleo, señuelo al que se vincula una suerte de esclavitud (sexual) por deudas para reintegrar el coste del viaje migratorio (vid. sentencia de la sala penal del Tribunal Supremo núm. 538/2016, de 17 de junio, sobre ciudadanas extranjeras atraídas bajo promesa de empleo como peluqueras), lo que puede provocar un concurso ideal de delitos (sentencia del Tribunal Supremo, sala penal, núm. 214/2017, de 29 de marzo).

La doctrina judicial social también ha recurrido, tanto la jurisprudencia como la doctrina de los Tribunales Superiores de Justicia, a la pirueta imposible de excluir el estudio de la prostitución y resolver únicamente sobre la relación de alterne, para considerarla laboral por lícita (sentencias del Tribunal Supremo, sala social, de 3 de marzo de 1981, de 25 de febrero de 1984, de 14 de mayo de 1985, de 21 de octubre de 1987, o de 4 de febrero de 1988, y las posteriores que han seguido la misma doctrina).

A título de ejemplo, en la sentencia del Tribunal Superior de Justicia de Galicia núm. 4816/2009, de 4 de noviembre, se afirma literalmente que "la actividad de alterne no suele ser, en la práctica, actividad pura de alterne, sino actividad de alterne asociada a la actividad de explotación de la prostitución ajena", y, como tal es "una forma de violencia de género, de esclavitud de las mujeres y de actividad contraria a la moral", "de donde nunca serviría de base para una relación laboral lícita, aun estando asociada al alterne" (sentencia del mismo tribunal de 10 de noviembre de 2004, dictada en el recurso de suplicación núm. 3598/2004). Como cabe apreciar, la alusión a la prostitución como forma de esclavitud se efectúa prescindiendo de su carácter forzado o no, si bien no es este un pronunciamiento habitual en la doctrina de los tribunales españoles, que omiten resolver al respecto, al amparo de la ilicitud del objeto de esta hipotética relación laboral. El mismo tribunal citado reitera en sendas sentencias posteriores, de 12 de marzo de 2008 (recurso núm. 6467/2007), núm. 1966/2013, de 10 de abril, o de 6 de octubre de 2017 (dictada en el recurso núm. 3207/2017), la imposibilidad de asimilar contrato de trabajo y "tráfico sexual" ("resulta jurídicamente inadmisible que el tráfico sexual retribuido en que 
APROXIMACIÓN LABORAL A LOS CONCEPTOS DE ESCLAVITUD, TRABAJO FORZOSO Y EXPLOTACIÓN LABORAL

la prostitución consiste pueda reputarse subsumible, vía contrato de trabajo, en el ejercicio regular del poder dirección empresarial en los términos en que se regulan en el art. 20 del ET") ${ }^{48}$.

Por su parte, la sala social del Tribunal Supremo, admitida en las sentencias de los años ochenta citadas la laboralidad del alterne, excluye de su conocimiento la cuestión, apelando a un motivo formal, cual es la necesaria contradicción entre sentencias cuya casación para la unificación de doctrina se pretende, evitando, por tanto, pronunciarse al respecto (en este sentido, las sentencias núm. 61/2013, de 29 de octubre de 2013 y núm. 1099/2016, de 21 de diciembre, o los autos de 18 de junio y 11 de septiembre de 2014, de 15 de diciembre de 2015 o de 11 de mayo de 2016). No contamos, por tanto, con una elaboración jurisprudencial del concepto ni de las fronteras con la esclavitud y la trata, pues en muy pocos casos se valora la posible existencia de una situación de trata, pero de la incursión en el tema de toda la doctrina judicial sí cabe extraer un elemento común: en ningún caso existe pronunciamiento sobre el iter que ha llevado al ejercicio de la actividad en sí, que solo cuestiona alguna resolución judicial inferior (cfr. sentencia del juzgado de lo social número 10 de Barcelona, de 18 de febrero de 2015, dictada en el procedimiento núm. 835/2013, donde se sienta como premisa la necesidad de distinguir entre la prostitución forzada y la voluntaria, única esta última sobre la que se reconoce la competencia de la jurisdicción social, pues la primera nunca podría ser objeto de pronunciamiento en dicho orden jurisdiccional en orden a debatir su pretendido carácter laboral).

\subsection{Limitación del derecho de libertad}

Finalmente, en un escalón inferior del concepto de "trabajo forzoso" se encuentra un tertium genus, en el que el carácter forzoso de la prestación se desvincula por completo y claramente de la dignidad de la persona y se vincula exclusivamente al derecho a la libertad en la toma de decisiones.

El derecho comprometido en este caso es exclusivamente la libertad de decisión, sin que concurra sometimiento a condiciones laborales irregulares ni abusivas ${ }^{49}$. Se trataría de la obligación de realizar ciertas prestaciones, distintas de las de naturaleza pública o cívica impuestas por la legislación nacional en cada caso.

A título de ejemplo, la sentencia del TEDH de 18 de octubre de 2011, en el caso Graziani-Weiss contra Austria, analiza la alegada violación de la prohibición de trabajo forzoso por parte de letrado "obligado" a ejercer la función de tutor legal de persona con enfermedad mental por nombramiento de oficio. La citada resolución concluye que tal función se integra en los deberes inherentes a un abogado en ejercicio, sin que la medida pueda considerarse desproporcionada. Por tanto, excluye la aplicabilidad del concepto de trabajo forzoso.

48 En la sentencia núm. 304/2015, de 16 de enero, asi como en la núm. 2681/2016, de 6 de mayo, la actividad de alterne es preparatoria de la de prostitución, por lo que deduce el tribunal que no se podría hacer una tal separación de manera que la ilicitud de una parte del contrato lleva a la del todo.

49 Para Urrutikoetxea, el "trabajo coactivo con limitaciones de la libertad del trabajador" se articula sobre cuatro ejes "1. asegurar el suministro de mano de obra 2. reducción de costes (e intensificación de la explotación) 3. una matriz disciplinaria 4. la articulación de un doble mercado (exógeno/endógeno)", que actúan de forma combinada (Urrutikoetxea Barrutia, Mikel, cit, p. 396). 


\section{CONCLUSIONES}

En el marco del trabajo y del trabajo lucrativo, las fronteras entre la esclavitud con fines de explotación económica (incluida la de carácter sexual) y el trabajo forzoso vienen delimitadas por la propia acción normativa de la Organización Internacional del Trabajo. Si bien algunos casos presentan rasgos indisolubles comunes a ambas figuras, la detallada descripción del fenómeno del trabajo forzoso por parte de la OIT permite afirmar que las distintas formas de esclavitud laboral conllevan trabajo forzoso, pero no así al revés, pues el trabajo forzoso no constituye, en la descripción matizada especialmente por los informes de la citada organización de Naciones Unidas, una forma específica de esclavitud per se, en tanto el concepto incluye formas más debilitadas de coacción o intimidación con fines de lucro económico, en la que la persona no es usada según los atributos de la propiedad características de toda forma de esclavitud, específicamente contemporánea, donde los tribunales internacionales de derechos humanos han descartado la propiedad o posesión de la persona en favor del uso de los atributos propios de aquella.

En sus formas más "refinadas", a tenor del análisis e interpretación auténtica de la propia OIT a través de sus informes, el trabajo forzoso puede identificarse con situaciones caracterizadas por un débil vínculo de intimidación, siendo paradigmático el caso de la realización (forzosa) de horas extraordinarias o prolongación de la jornada de trabajo, bajo las circunstancias específicas descritas en páginas anteriores. Sin duda existe un abismo conceptual y fáctico entre este supuesto y la explotación extrema basada en la coacción física o la intimidación en condiciones incluso infrahumanas, propias de los casos más extremos descritos con anterioridad.

Por otra parte, la explotación sexual, siendo una forma de esclavitud con fines de obtener lucro económico, presenta rasgos específicos y propios, que se conjugan con una necesaria perspectiva de género que el análisis del problema requiere, y en los que se combinan dos escenarios distintos: uno el de la trata con tales fines, la figura paradigmática por ser central en este tema, y el otro el de la explotación sexual forzada sin trata, supuesto prácticamente testimonial, en tanto la realidad demuestra que los grises en la escala de gravedad de estas formas de explotación de la persona no existen, pasando de la trata al ejercicio voluntario de la prostitución, otro supuesto escasamente relevante tanto estadística como analíticamente. En cualquier caso, desde la perspectiva laboral, la cuestión central es que esta forma de explotación directa de la persona y no de su fuerza de trabajo es una forma de esclavitud con fines lucrativos.

Finalmente, el análisis de la jurisprudencia europea y latinoamericana sobre el particular arroja una inquietante doble perspectiva en el análisis de los casos que envuelven a mujeres, a menudo calificados como servidumbre, frente a los que se conceptúan como formas más graves de trabajo coactivo. 


\section{BIBLIOGRAFÍA}

Anguita Olmedo, Concepción: "El tráfico ilegal de seres humanos para la explotación sexual y laboral: la esclavitud del siglo XXI", Nómadas: Critical Journal of Social and Juridical Sciences, núm. 15, 2007.

Ayala Sánchez, Alberto, y Bernal Santamaría, Francisca: “Prácticas no laborales: La nueva esclavitud del siglo XXI en las relaciones laborales", AA.VV. (Monereo Pérez, José Luis, dir.): Retos del Derecho del Trabajo frente el desempleo juvenil. Comunicaciones: XXXII Jornadas Universitarias Andaluzas de Derecho del Trabajo y Relaciones Laborales, Consejo Andaluz de Relaciones Laborales, 2014, pp. 491-507.

Ballesteros Doncel, Esmeralda: "China Blue, Formas contemporáneas de esclavitud laboral", Cuadernos de relaciones laborales, Vol. 33, núm. 2, 2015 (Las pensiones de jubilación: una perspectiva alternativa), pp. 462-466.

Bonet Pérez, Jordi: "La interpretación de los conceptos de esclavitud y de otras prácticas análogas a la luz de ordenamiento jurídico internacional: Aproximación teórica y jurisdiccional", En AA.VV. (Esteban Juan Pérez Alonso, Pedro Mercado Pacheco, Sofía Olarte Encabo, Ángeles Lara Aguado, María Inmaculada Ramos Tapia, Esther Pomares Cintas, Patricia Esquinas Valverde, coords.): El derecho ante las formas contemporáneas de esclavitud, Tirant lo Blanch, 2017, pp. 183-210.

Boronat Tormo, Mercedes y Grima Lizandra, Vicente: "La esclavitud y la servidumbre en el derecho español. A propósito de la STEDH de 26 de julio de 2005 ("Siliadin vs. Francia"): un caso de trabajo doméstico servil", en Carbonell Mateu, J. C.; González Cussac, J. L.; Orts Berenguer, E. y Cuerda Arnau, Ma . L. (Coord.), Constitución, derechos fundamentales y sistema penal: (Semblanzas y estudios con motivo del setenta aniversario del profesor Tomás Salvador Vives Antón), vol. 1, 2009, pp. 257-286.

Cavas Martínez, Faustino: "Trabajo libre, trabajo digno: revisando viejas ideas a propósito de un reciente informe de la OIT sobre el trabajo forzoso en el mundo", en Aranzadi social, núm. 5, 2001, pp. 83-96.

De la Cuesta Aguado, Paz: Mujeres inmigrantes y siniestralidad laboral: acoso, explotación y esclavitud. Revista de derecho social, ISSN 1138-8692, núm. 41, 2008, pp. 75-93.

García Schwarz, Rodrigo: Rompiendo las cadenas de una ciudadanía cautiva. De los derechos sociales a los derechos humanos fundamentales. La lucha contra el trabajo esclavo contemporáneo. Tesis doctoral dirigida por Laura Mora Cabello de Alba (dir. tes.). Universidad de Castilla-La Mancha (2010).

Gil Montero, Raquel: “Presentación: servidumbre, esclavitud y libertad”, Población \& sociedad, Vol. 27, núm. 2, 2020 , pp. 1-7.

Guisasola Lerma, Cristina: "Formas contemporáneas de esclavitud y trata de seres humanos: una perspectiva de género", Estudios penales y criminológicos, ISSN 1137-7550, núm. 39, 2019, pp. 175-215, en https://dialnet.unirioja.es/servlet/articulo?cod igo $=6976384 \&$ orden $=0 \&$ info $=$ link.

Lerussi, Romina: "Servidumbres domésticas en contextos latinoamericanos: Aproximaciones socio-jurídicas". En AA.VV. (Esteban Juan Pérez Alonso, Pedro Mercado Pacheco, Sofía Olarte Encabo, Ángeles Lara Aguado, María Inmaculada Ramos Tapia, Esther Pomares Cintas, Patricia Esquinas Valverde, coords.): El derecho ante las formas contemporáneas de esclavitud, Tirant lo Blanch, 2017, pp. 757-774. 
López Rodríguez, Josune, y Arrieta Idiakez, Francisco Javier: "La trata de seres humanos con fines de explotación laboral en la legislación española", ICADE. Revista cuatrimestral de las Facultades de Derecho y Ciencias Económicas y Empresariales, núm. 107, 2019, DOI: https://doi.org/10.14422/icade.i107.y2019.002.

Lousada Arochena, J. Fernando: "Normativa internacional contra la explotación humana y laboral en el trabajo doméstico: La ONU y la OIT", Lan harremanak: Revista de relaciones laborales, núm. 39, 2018 (Centenario de la Organización Internacional del Trabajo (OIT)/Lanaren Nazioarteko Erakundearen (LANE) Mendeurrena), pp. 152-187, en https://dialnet.unirioja.es/ descarga/articulo/6550623.pdf.

Lousada Arochena, J. Fernando. "El tratamiento legal de la prostitución: ¿Forma de esclavitud o trabajo sexual?", En AA.VV. (Esteban Juan Pérez Alonso, Pedro Mercado Pacheco, Sofía Olarte Encabo, Ángeles Lara Aguado, María Inmaculada Ramos Tapia, Esther Pomares Cintas, Patricia Esquinas Valverde, coords.): El derecho ante las formas contemporáneas de esclavitud, Tirant lo Blanch, 2017, pp. 632-654.

Martín Morales, Ricardo: "Las nuevas formas de esclavitud en los textos constitucionales y declaraciones de derechos", En AA.VV. (Esteban Juan Pérez Alonso, Pedro Mercado Pacheco, Sofía Olarte Encabo, Ángeles Lara Aguado, María Inmaculada Ramos Tapia, Esther Pomares Cintas, Patricia Esquinas Valverde, coords.): El derecho ante las formas contemporáneas de esclavitud, Tirant lo Blanch, 2017, pp. 281-305.

Miñarro Yanini, Margarita: «Formas esclavas de trabajo y servicio del hogar familiar: delimitación conceptual, problemática específica y propuestas (1), Relaciones Laborales, n. ํ 10, Sección Doctrina, octubre 2014, Año 30, pp. 71 y ss.

OIT: Informe de la Comisión de Expertos en Aplicación de Convenios y Recomendaciones, Informe III (Parte IV), Conferencia Inter-

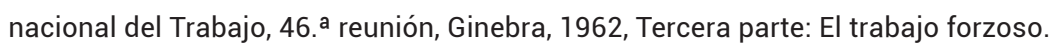

OIT: Informe Global de la OIT, El costo de la coacción, 5 de diciembre de 2009, en http://www.ilo.org/wcmsp5/groups/public/--ed_norm/---declaration/documents/publication/wcms_106269.pdf.

OIT: Informe III (Parte 1B). Estudio general relativo al Convenio sobre el trabajo forzoso, 1930 (núm. 29), y al Convenio sobre la abolición del trabajo forzoso, 1957 (núm. 105). Conferencia Internacional del Trabajo 96. a reunión, 2007. Publicado en http:// www.ilo.org/wcmsp5/groups/public/---ed_norm/---relconf/documents/meetingdocument/wcms_089201.pdf.

OIT: La libertad sindical, Recopilación de decisiones y principios del Comité de Liberad Sindical del Consejo de Administración de la OIT, Ginebra, Oficina Internacional del Trabajo, quinta edición (revisada), 2006.

Olarte Encabo, Sofía: "La doctrina del Tribunal Europeo de derechos humanos sobre esclavitud, servidumbre y trabajo forzado: Análisis crítico desde la perspectiva laboral", Temas laborales: Revista andaluza de trabajo y bienestar social, núm. 145, 2018 (La jurisprudencia del Tribunal Europeo de Derechos Humanos en materia laboral. In memoriam José Vida Soria), pp. 55-86.

Pacecca, María Inés: "Trabajo, explotación laboral, trata de personas. Categorías en cuestión en las trayectorias migratorias". Revista Interdisciplinar da Mobilidade Humana: REMHU, Vol. 19, núm. 37, 2011 (REMHU: "Tráfico de pessoas"), en http:// remhu.csem.org.br/index.php/remhu/article/view/281.

Pomares Cintas, Esther: "El delito de trata de seres humanos con finalidad de explotación laboral". Revista electrónica de ciencia penal y criminología, núm. 13, 2011, en http://criminet.ugr.es/recpc/13/recpc13-15.pdf. 
Pomares Cintas, Esther: "Directrices para el análisis y persecución penal de la explotación económica en condiciones de esclavitud o similares". En AA.VV. (Esteban Juan Pérez Alonso, Pedro Mercado Pacheco, Sofía Olarte Encabo, Ángeles Lara Aguado, María Inmaculada Ramos Tapia, Esther Pomares Cintas, Patricia Esquinas Valverde, coords.): El derecho ante las formas contemporáneas de esclavitud, Tirant lo Blanch, 2017, pp. 775-794.

Rivas Vallejo, Pilar: "Las fronteras entre los conceptos de esclavitud, trabajo forzoso y explotación: perspectiva laboral y de género", en AA.VV. (Pedro Mercado Pacheco, María Inmaculada Ramos Tapia; Esteban Juan Pérez Alonso, Sofía Olarte Encabo, dirs.): Formas contemporáneas de esclavitud y derechos humanos en clave de globalización, género y trata de personas, Tirant lo Blanch, 2020, pp. 39-90.

Rivas Vallejo, Pilar: "Aspectos laborales de la prostitución voluntaria: Perspectiva comunitaria y modelos comparados". En AA.VV. (Esteban Juan Pérez Alonso, Pedro Mercado Pacheco, Sofía Olarte Encabo, Ángeles Lara Aguado, María Inmaculada Ramos Tapia, Esther Pomares Cintas, Patricia Esquinas Valverde, coords.): El derecho ante las formas contemporáneas de esclavitud, Tirant lo Blanch, 2017, pp. 569-597.

Rodríguez-Piñero y Bravo-Ferrer, Miguel: "La libertad de trabajo y la interdicción del trabajo forzoso", Relaciones Laborales, núm. 1, quincena del 1 al 15 de enero 2011, año 27, tomo 1, 3-16.

Rojo Torrecilla, Eduardo: "Nueva esclavitud y trabajo forzoso: un intento de delimitación conceptual desde la perspectiva laboral", en AA.VV. (Esteban Juan Pérez Alonso, Pedro Mercado Pacheco, Sofía Olarte Encabo, Ángeles Lara Aguado, María Inmaculada Ramos Tapia, Esther Pomares Cintas, Patricia Esquinas Valverde, coords.): El derecho ante las formas contemporáneas de esclavitud, Tirant lo Blanch, 2017, pp. 721-755.

Salas Porras, María: "Trabajador esclavo y contrato de esclavo: configuración jurídica", Revista Critica de Historia de las Relaciones Laborales y de la Política Social. 2014, reimpresión en número 38, 2016, en http://www.eumed.net/rev/historia/08/ contrato-esclavo.html.

Salcedo Beltrán, María del Carmen: "El trabajo doméstico en España: planteamientos y desafíos insoslayables frente a la "esclavitud moderna"'". Revista General de Derecho del Trabajo y de la Seguridad Social, núm. 55, 2020.

Shaninian, Gulnara: "Aproximación a la realidad de las formas contemporáneas de esclavitud". En AA.VV. (Esteban Juan Pérez Alonso, Pedro Mercado Pacheco, Sofía Olarte Encabo, Ángeles Lara Aguado, María Inmaculada Ramos Tapia, Esther Pomares Cintas, Patricia Esquinas Valverde, coords.): El derecho ante las formas contemporáneas de esclavitud, Tirant lo Blanch, 2017, pp. 31-51.

Shahinian, Gulnara: "La servidumbre doméstica: un problema mundial de derechos humanos" - Informe de la Relatora Especial sobre las formas contemporáneas de esclavitud, documento A/HRC/15/20, en www.acnur.org.

Skrivankova, Klara: Between decent work and forced labour: examining the continuum of exploitation, 2010, pp. 17 y ss.

Terradillos Basoco, Juan María: "Explotación laboral, trabajo forzoso, esclavitud. ¿Retos político-criminales para el siglo XXI?", en AA.VV. (Eduardo Demetrio Crespo, dir., y Manuel Maroto Calatayud y María Pilar Marco Francia, coords.): Derecho penal económico y derechos humanos, Tirant lo Blanch, 2018, pp. 215-243.

Urrutikoetxea Barrutia, Mikel: "No se ve, no se toca y sin embargo, existe: La esclavitud hoy. Hacia una reconceptualización del trabajo esclavo", Lan harremanak: Revista de relaciones laborales, núm. 35, 2017, pp. 389-416. 
APROXIMACIÓN LABORAL A LOS CONCEPTOS DE ESCLAVITUD, TRABAJO FORZOSO Y EXPLOTACIÓN LABORAL

Valverde Cano, Ana Belén: "It's all about control: el concepto de trabajos forzosos", Revista de Derecho Penal y Criminología, núm. 22, 2019, pp. 239-299.

Villacampa Estiarte, Carolina: "La moderna esclavitud y su relevancia jurídico-penal", Revista de derecho penal y criminología, 3. a Época, n. ${ }^{\circ} 10$ (julio de 2013), pp. 293-342, http://e-spacio.uned.es/fez/eserv/bibliuned:revistaDerechoPenalyCriminolog ia-2013-10-4035/Documento.pdf. 